\title{
Hydroxyl layer: trend of number density and intra-annual variability
}

\author{
G. R. Sonnemann ${ }^{1,2}$, P. Hartogh ${ }^{2}$, U. Berger ${ }^{1}$, and M. Grygalashvyly ${ }^{1}$ \\ ${ }^{1}$ Leibniz Institute of Atmospheric Physics at the University Rostock in Kühlungsborn, Schloss-Str. 6, \\ 18225 Ostseebad Kühlungsborn, Germany \\ ${ }^{2}$ Max Planck Institute for Solar System Research, Justus-von-Liebig-Weg 3, 37077 Göttingen, Germany \\ Correspondence to: G. R. Sonnemann (sonnemann@iap-kborn.de)
}

Received: 21 January 2015 - Revised: 10 May 2015 - Accepted: 20 May 2015 - Published: 17 June 2015

\begin{abstract}
The layer of vibrationally excited hydroxyl $\left(\mathrm{OH}^{*}\right)$ near the mesopause in Earth's atmosphere is widely used to derive the temperature at this height and to observe dynamical processes such as gravity waves. The concentration of $\mathrm{OH}^{*}$ is controlled by the product of atomic hydrogen, with ozone creating a layer of enhanced concentration in the mesopause region. However, the basic influences on the $\mathrm{OH}^{*}$ layer are atomic oxygen and temperature. The long-term monitoring of this layer provides information on a changing atmosphere. It is important to know which proportion of a trend results from anthropogenic impacts on the atmosphere and which proportion reflects natural variations. In a previous paper (Grygalashvyly et al., 2014), the trend of the height of the layer and the trend in temperature were investigated particularly in midlatitudes on the basis of our coupled dynamic and chemical transport model LIMA (Leibniz Institute Middle Atmosphere). In this paper we consider the trend for the number density between the years 1961 and 2009 and analyze the reason of the trends on a global scale. Further, we consider intra-annual variations. Temperature and wind have the strongest impacts on the trend. Surprisingly, the increase in greenhouse gases (GHGs) has no clear influence on the chemistry of $\mathrm{OH}^{*}$. The main reason for this lies in the fact that, in the production term of $\mathrm{OH}^{*}$, if atomic hydrogen increases due to increasing humidity of the middle atmosphere by methane oxidation, ozone decreases. The maximum of the $\mathrm{OH}^{*}$ layer is found in the mesopause region and is very variable. The mesopause region is a very intricate domain marked by changeable dynamics and strong gradients of all chemically active minor constituents determining the $\mathrm{OH}^{*}$ chemistry. The $\mathrm{OH}^{*}$ concentration responds, in part, very sensitively to small changes in these parameters.
\end{abstract}

The cause for this behavior is given by nonlinear reactions of the photochemical system being a nonlinear enforced chemical oscillator driven by the diurnal-periodic solar insolation. At the height of the $\mathrm{OH}^{*}$ layer the system operates in the vicinity of chemical resonance. The solar cycle is mirrored in the data, but the long-term behavior due to the trend in the Lyman- $\alpha$ radiation is very small. The number density shows distinct hemispheric differences. The calculated $\mathrm{OH}^{*}$ values show sometimes a step around a certain year. We introduce a method to find out the date of this step and discuss a possible reason for such behavior.

Keywords. Atmospheric composition and structure (airglow and aurora; middle atmosphere - composition and chemistry; pressure density and temperature)

\section{Introduction}

In a previous paper (Grygalashvyly et al., 2014), we discussed the trend in height of the vibrationally excited hydroxyl $\left(\mathrm{OH}^{*}\right)$ layer and considered further important aeronomic parameters dependent on changed dynamical quantities, such as temperature and wind components, increase in anthropogenic greenhouse gases (GHGs), and Lyman- $\alpha$ radiation flux, in northern midlatitudes. The description of the model and the treatment of the calculation of excited $\mathrm{OH}^{*}$ is extensively given in the above paper and shall not be repeated here. However, we recap here the main points of the numerical experiments and the main results. These results are based on calculations made by the chemical transport model (CTM) using dynamical parameters (wind components, pressure, and temperatures) from the LIMA (Leibniz 
Institute Middle Atmosphere) model (e.g., chemistry and dynamics in Sonnemann et al., 1994, 1998, 2005, 2006a, 2006b, 2007, 2008; Grygalashvyly and Sonnemann, 2006; dynamics only in Berger, 2008; Lübken et al., 2009, 2013). The dynamical part of the model LIMA employs for all model runs the real increase in $\mathrm{CO}_{2}$ and ozone concentration (Lübken et al., 2013). The most important difference to the precursor model COMMA-IAP (COlogne Model of the Middle Atmosphere of the Institute of Atmospheric Physics) is that LIMA assimilates ECMWF (European Centre for Medium-Range Weather Forecasts) data (Uppala et al., 2005) for temperature and horizontal wind components below $35 \mathrm{~km}$, dating back to 1961. These data contain information about waves propagating into the mesosphere and lower thermosphere (MLT) region. In the horizontal plane LIMA uses so-called triangle or simplex coordinates marked by distances between the grid points of about $110 \mathrm{~km}$.

In order to separate the influence of the growing concentration of GHGs, the varying solar radiation and the impact of the changeable dynamics, we carried out three computer experiments as also described in Grygalashvyly et al. (2014). The trend analysis covers a range from the years 1961 to 2009.

Firstly, a so-called reference run (A), termed the "realistic case" using all "realistic input data" calculated by LIMA, was executed. "Realistic input data" from LIMA are based on observations of GHGs $\left(\mathrm{CO}_{2}\right.$ and $\mathrm{O}_{3}$ in particular), Lyman- $\alpha$ flux, and ECMWF data assimilated in the dynamical part of the model (see also Berger 2008; Lübken et al., 2013). In the chemical part, the growth of GHGs $\left(\mathrm{CH}_{4}, \mathrm{CO}_{2}, \mathrm{~N}_{2} \mathrm{O}\right)$ at the lower border and Lyman- $\alpha$ flux are parameterized by data of measurements (see Grygalashvyly et al., 2014).

In a second run (B), the Lyman- $\alpha$ radiation flux in the CTM was fixed on a value corresponding to an absolute solar minimum year with a flux of $3.42 \times 10^{11}$ photons $\mathrm{cm}^{-2} \mathrm{~s}^{-1}$. The other influences again varied in realistic terms.

Finally, in a third run (C), the GHGs in the CTM were held constant on the 1961 level, but the CTM used LIMA dynamics variable from year to year and the Lyman- $\alpha$ radiation varied in realistic terms. Note that the dynamics and temperature in all numerical experiments are identical.

Although the whole system is internally nonlinearly linked (Sonnemann and Fichtelmann, 1997; Feigin et al., 1998), the difference between the realistic case and the cases in which one impact on the trend is held constant should mirror, to first order, the separate influence of the respective impact. Thus, the direct photochemical effect (DPE) of Lyman- $\alpha$ (only due to photodissociation and successive chemical reactions, without taking into account the effect of modulation of the dynamics and temperature, and consecutive impact on chemical species) on minor chemical constituents in the MLT region is calculated as the difference of run A - run B. The direct chemical effect (DCE) of growth of GHGs (defined analogously to the direct photochemical effect) is the difference of run $\mathrm{A}$ - run $\mathrm{C}$. In order to consider the effect of dynamics and temperature, we remove from the realistic run (A) the DPE of Lyman- $\alpha$ and DCE of GHGs (run A - (run A - run B) $-(\operatorname{run} A-\operatorname{run} C)=\operatorname{run} B+\operatorname{run} C-\operatorname{run} A)$.

The main finding concerning the $\mathrm{OH}^{*}$ layer was that the chief reason for a decreasing trend in height of the $\mathrm{OH}^{*}$ layer results from the shrinking of the middle atmosphere (SMA effect) due to cooling by $\mathrm{CO}_{2}$ and declining stratospheric ozone. The DCE due to increase in GHGs slightly compensate for the decreasing trend caused by cooling. Evidently, according to the expression (10) from Grygalashvyly et al. (2014) the height of peak of the $\mathrm{OH}^{*}$ layer is inversely proportional to atomic oxygen number density. The most chemically important GHG is methane, which increases the humidity of the middle atmosphere. Consequently it reduces odd oxygen (and particularly atomic oxygen) in the mesopause region. Hence, DCE of GHGs moves the $\mathrm{OH}^{*}$ layer upward. Analogously, $\mathrm{N}_{2} \mathrm{O}$, transformed into odd nitrogen, reduces odd oxygen. However, $\mathrm{CO}_{2}$ cools the upper atmosphere, but it only has, in contrast to the changing humidity, a marginal DCE on the $\mathrm{OH}$ chemistry. The long-term trend in the Lyman- $\alpha$ radiation flux has only a minor decreasing impact; however, this is not true if considering the impact of the 11-year solar cycle, which is clearly imprinted in the data. There is a very faint bias in the Lyman- $\alpha$ trend as a result of a limited analyzed period of 49 years, which comprises four solar cycles plus 3 years. The period starts in 1961, 3 years before the solar minimum in 1964, and it ends in 2009, close to the most previous minimum.

We have to distinguish between the trend in geometric coordinates and the trend in pressure coordinates. The trend at levels of constant pressure is small and sometimes opposite to the trend in geometrical coordinates. The cause for this behavior results from the SMA effect. The behavior also depends strongly on latitude and season. In spite of the huge amount of calculated data, some presented in Grygalashvyly et al. (2014), a large number of questions related to the $\mathrm{OH}^{*}$ layer still remain open.

Whereas the long-term trend of the $\mathrm{OH}^{*}$-layer altitude in the middle atmosphere is mainly determined by the SMA effect, the trend in the number density is, at a first glance, more influenced by the rising GHGs - in particular by the trend in methane $\left(\mathrm{CH}_{4}\right)$. Methane is oxidized to water vapor, as it is the source of chemically very active hydrogen radicals formed after photolysis of water vapor or by its oxidation by $\mathrm{O}\left({ }^{1} \mathrm{D}\right)$. In this paper, we are especially interested in the change in the concentration of the $\mathrm{OH}^{*}$ layer on a global scale.

The trend in a chemical constituent can be influenced by both the production and the loss term. Equations (1) to (3) in Grygalashvyly et al. (2014) contain a large number of individual expressions involved in the formation of the $\mathrm{OH}^{*}$ layer. However, most of them are of only minor importance. The $\mathrm{OH}^{*}$ density (determining the nightglow brightness) was investigated among many others by von Zahn et al. (1987), Offermann and Gerndt (1990), Taylor et al. (1991, 
1995a, 1995b, 1997), Yee et al. (1997), She and Lowe (1998), Scheer and Reisin (2000, 2010), Bittner et al. (2000, 2002), Yamada et al. (2001), Liu and Shepherd (2006), Reisin and Scheer (2004, 2009), Espy et al. (2007), Mulligan et al. (2009), Xu et al. (2010, 2012), and von Savigny et al. (2012, 2015). In an earlier paper, Yee et al. (1997) stated that the quantitative comparison between theoretical and experimental brightness is rather poor. The situation is not much better 17 years later. It was supposed that tides and short-timescale gravity waves could be responsible for this finding. However, as we will discuss later, the $\mathrm{OH}^{*}$ chemistry in the height of the $\mathrm{OH}^{*}$ layer is rather intricate.

The paper is structured as follows. In Sect. 2 some chemical aspects linked with the $\mathrm{OH}^{*}$ layer are discussed. Then in Sect. 3 we present trends based on results of our model calculations. Section 4 deals with correlations between some parameters influencing the $\mathrm{OH}^{*}$ layer and considers intraannual periods derived from the calculated data. In Sect. 5 we discuss the results. Finally, in Sect. 6 we present conclusions that can be drawn from results and summarize the most important findings.

\section{Some theoretical aspects of the chemistry in the MLT region}

The mesopause region is a very intricate domain. It is the border between the domain where solar-induced variations dominate (above) and the domain where mainly meteorological influences determine the variability (below). The zonal wind has a considerable impact on the upper mesospheric chemistry (Sonnemann, 2001; Sonnemann and Grygalashvyly, 2003; Hartogh et al., 2011). This impact is called the photochemical Doppler effect and it is marked by the fact that the zonal wind changes the period of solar insolation (by up to few hours) to which an air parcel, moving with or against the Earth's rotation, is subjected. Particularly during sunset when the system switches from the daytime state, dominated by dissociating solar insolation, into the nighttime state without photodissociation - the zonal wind considerably influences the nighttime ozone level. A zonal wind blowing with the rotation of the Earth shortens the time of sunset to which an air parcel is subjected and increases the nighttime ozone level. The effect is strongest there where the duration of sunset ranges on the order of the chemical system time (and that is roughly between 70 and $80 \mathrm{~km}$ ), influencing such a phenomenon as the tertiary ozone maximum in high-latitude winter (Hartogh et al., 2011).

$\mathrm{OH}^{*}$ and $\mathrm{OH}$ possess marked diurnal and annual variations resulting from the interplay of the chemically active constituents and the variation in its source gases, water vapor, and ozone. However, the variations in temperature, eddy diffusion, pressure, and gravity wave activity are also rather important. The photolysis of water vapor is the main net production term of hydrogen radicals and to a lesser degree also the oxidation of molecular hydrogen and water vapor by $\mathrm{O}\left({ }^{1} \mathrm{D}\right)$ produced by the photodissociation of ozone. In the mesopause region the vertical flux of atomic hydrogen and atomic oxygen plays an important role in the chemistry. The main production terms determining the current concentration of $\mathrm{OH}$ are the reaction of atomic hydrogen with ozone and to a lesser degree the reaction of $\mathrm{HO}_{2}$ with atomic oxygen. The chief loss of $\mathrm{OH}$ takes place by the reaction with atomic oxygen. The main reactions, also determining the odd-oxygendestroying catalytic cycle, are as follows:

$\mathrm{H}+\mathrm{O}_{3} \rightarrow \mathrm{OH}+\mathrm{O}_{2}$

$\mathrm{OH}+\mathrm{O} \rightarrow \mathrm{H}+\mathrm{O}_{2}$

net: $\mathrm{O}+\mathrm{O}_{3} \rightarrow 2 \mathrm{O}_{2}$.

From these reactions, the $\mathrm{OH}$ concentration approximately follows to

$[\mathrm{OH}]=l_{1}[\mathrm{H}]\left[\mathrm{O}_{3}\right] / l_{2}[\mathrm{O}]$

where $l_{1}$ represents the reaction rates for the respective reactions according to Sander et al. (2006). All further reaction rates are taken from this review. Eq. (1) makes it clear that the $\mathrm{OH}$ concentration depends on the concentration of the other important chemically active constituents, which are $\mathrm{H}$, $\mathrm{O}$, and $\mathrm{O}_{3}$. The individual characteristic chemical time of $\mathrm{OH}$ is very short (on the order of seconds or even below that), so that the $\mathrm{OH}$ concentration is almost in a floating equilibrium immediately following the changing concentration of the involved constituents.

The first reaction of the catalytic cycle is actually not completely correct, because then $\mathrm{OH}$ is formed in vibrationally excited states $\mathrm{OH}^{*}$ with $v=1-9$. However, the main loss of the excitation takes place by quenching through collisions with air particles (most effective with $\mathrm{O}_{2}$ ), resulting finally in deactivated OH. Disregarding the stepwise deactivation of $\mathrm{OH}^{*}$ as described in Grygalashvyly et al. (2014), the equilibrium concentration of excited $\mathrm{OH}^{*}$ can be coarsely calculated using

$\left[\mathrm{OH}^{*}\right]=l_{1}[\mathrm{H}]\left[\mathrm{O}_{3}\right] / \gamma[M]$,

where $\gamma$ represents an effective quenching rate and $[M]$ the air density. An additional effective quenching takes place via atomic oxygen.

We discuss only nighttime conditions here. During the night the ozone density, $\left[\mathrm{O}_{3}\right]$, can be approximately replaced by $\left[\mathrm{O}_{3}\right]=\mathrm{k}_{1}[\mathrm{O}]\left[\mathrm{O}_{2}\right][M] / l_{1}[\mathrm{H}]$ with the reaction rate $\mathrm{k}_{1}=6 \times 10^{-34}(300 / T)^{2.4} \mathrm{~cm}^{-6} \mathrm{~s}^{-1}$. Then Eq. (2) becomes $\left[\mathrm{OH}^{*}\right]=\left(\mathrm{k}_{1} / \gamma\right)[\mathrm{O}]\left[\mathrm{O}_{2}\right]$ depending on $[\mathrm{O}],\left[\mathrm{O}_{2}\right]$, and $T$. The characteristic time of ozone during the night amounts to $\tau_{\mathrm{O} 3}=1 / l_{1}[\mathrm{H}]$. At the height of the $\mathrm{OH}^{*}$ maximum the $\mathrm{H}$ density amounts to about $10^{8} \mathrm{~cm}^{-3}$ or often even larger, and the reaction rate is $l_{1}=1.4 \times 10^{-10} \exp (-460 / T)$ $\mathrm{cm}^{3} \mathrm{~s}^{-1}$. For $T=180 \mathrm{~K}$ the characteristic time then becomes $\tau_{\mathrm{O} 3}($ night $)=1288 \mathrm{~s} \approx 21 \mathrm{~min}$. Under these conditions ozone 


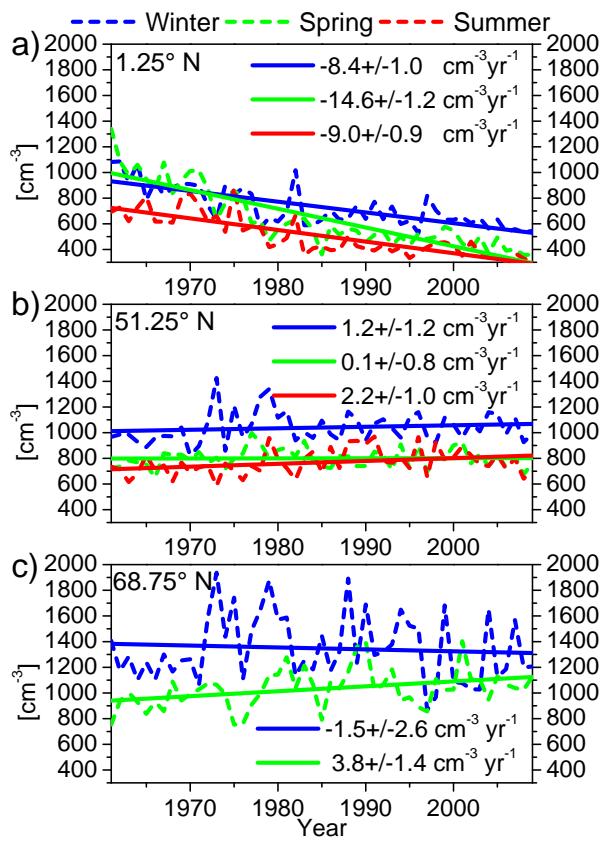

Figure 1. Long-term variations (dashed lines) and corresponding linear trends (solid lines) in the seasonally averaged nighttime mean concentration of the $\mathrm{OH}_{v=6}^{*}$ peak at low (a), middle (b), and high (c) northern latitudes for winter (blue lines), spring (green lines), and summer (red lines).

is in a quasi-floating equilibrium, followed by small lag in the changing minor constituents $\mathrm{O}$ and $\mathrm{H}$.

A first conclusion can be drawn if comparing Eq. (1) with (2), namely that the maximum of the $\mathrm{OH}$ layer is located below that of $\mathrm{OH}^{*}$. The proof is simple. The production terms are the same for both species but $\mathrm{O}$ decreases with decreasing height below its maximum at $95-100 \mathrm{~km}$, and the air density increases exponentially with decreasing height. The ratio of $\mathrm{OH}$ to $\mathrm{OH}^{*}$ is approximately given by

$[\mathrm{OH}] /\left[\mathrm{OH}^{*}\right]=\gamma[\mathrm{M}] / l_{2}[\mathrm{O}]$,

growing monotonically with decreasing height below the $\mathrm{O}$ maximum. Above $80 \mathrm{~km}$ height or a little higher, $\mathrm{OH}$ decreases strongly. This drop is mainly a result of the large loss by atomic oxygen by which concentration strongly increases up to its maximum at approximately 95 to $100 \mathrm{~km}$.

Over daytime the photolysis of chemically relatively inert constituents like water vapor or molecular oxygen results in the formation of chemically active species. Due to strong concentration gradients of these chemically active species, the vertical transport plays a very important role. In doing so, the transport takes place within chemical families. Its characteristic family time is deciding for the vertical transport. Because of the very short characteristic time on the order of $10^{-2} \mathrm{~s}$ at $87 \mathrm{~km}, \mathrm{OH}^{*}$ is practically in a floating equilibrium, meaning the concentration follows immediately the product
$[\mathrm{H}]\left[\mathrm{O}_{3}\right]$. The direct transport of $\mathrm{OH}^{*}$ itself can be neglected, but not the transport of the species forming $\mathrm{OH}^{*}$.

\section{Trends}

We use, as introduced in Grygalashvyly et al. (2014), the average between 00:00 and 03:00 LT as the $\mathrm{OH}^{*}$ nighttime value. All figures show averages from this time interval. It is evident that tides, as well as planetary waves (PWs) and gravity waves (GWs), also influence the chemistry. This particular time period of three nighttime hours can be influenced in a systematic manner by tides, so that a comparison with results from other latitude or seasons must consider this aspect. Identification of trends due to long-term changes in tides, PWs, and GWs is beyond the scope of this paper. In order to reduce the strong scatter, the data are still averaged over the season. Long-term monitoring of the $\mathrm{OH}^{*}$ layer was carried out, among others, by Lowe (2002), Reisin and Scheer (2002), Espy and Stegman (2002), Bittner et al. (2002), Beig et al. (2003), Offermann et al. (2003, 2006, 2010), Scheer et al. (2005), Beig (2011), and von Savigny (2015). However, most publications deal with temperature trends derived from long-term $\mathrm{OH}^{*}$ measurements.

A trend reflects the change in a parameter over 30 years. Often only long-term monitoring on the order of one decade or so are presented. Espy and Stegman (2002) analyzed OH radiance of a time series from 1991 to 1998 at $59.5^{\circ} \mathrm{N}$, $18.2^{\circ} \mathrm{E}$ and found a slight positive temperature and radiance trend, which is important in the context of the present paper. It is important to note that the trend is different for winter, equinoxes and summer. Von Savigny (2015) reported about long-term monitoring with SCIAMACHY on the Envisat satellite between 2003 and 2011. Offermann et al. (2010) published information regarding $\mathrm{OH}$ temperature at Wuppertal $\left(51^{\circ} \mathrm{N}, 7^{\circ} \mathrm{E}\right)$ in the period $1988-2008$ and found a decrease of $-0.23 \mathrm{~K} \mathrm{yr}^{-1}$ at $87 \mathrm{~km}$. Beig et al. (2003) collected published trends of a large number of groups in Table 5 of their paper.

Figure 1 exhibits the trend of the mean nighttime concentration of $\mathrm{OH}^{*}{ }_{v=6}$ at the peak averaged over the seasons winter (December, January, and February), spring (March, April, and May), and summer (June, July, and August) for high $\left(68.75^{\circ} \mathrm{N}\right)$, middle $\left(51.25^{\circ} \mathrm{N}\right)$, and low $\left(1.25^{\circ} \mathrm{N}\right)$ northern latitudes. We show, as commonly applied, the vibrational number $v=6$ in the trend figures.

At equatorial latitudes $\left(1.25^{\circ} \mathrm{N}\right.$, Fig. 1a) a negative trend of the $\mathrm{OH}^{*}$-peak number density occurs for all seasons, with largest values in the spring $\left(-14.6 \pm 1.2 \mathrm{~cm}^{-3} \mathrm{yr}^{-1}\right)$. The total reductions of the number density over 49 years (1961-2009) are $-409.9 \pm 50.3,-716.4 \pm 58.2$, and $-443.4 \pm 43.8 \mathrm{~cm}^{-3}$ for winter, spring, and summer, respectively. The figure shows a large year-to-year variability in all seasons. For instance, the maximum year-to-year variability (the difference between two consecutive years) amounts to $430 \mathrm{~cm}^{-3}$ for winter (1982/1983), $256 \mathrm{~cm}^{-3}$ for 


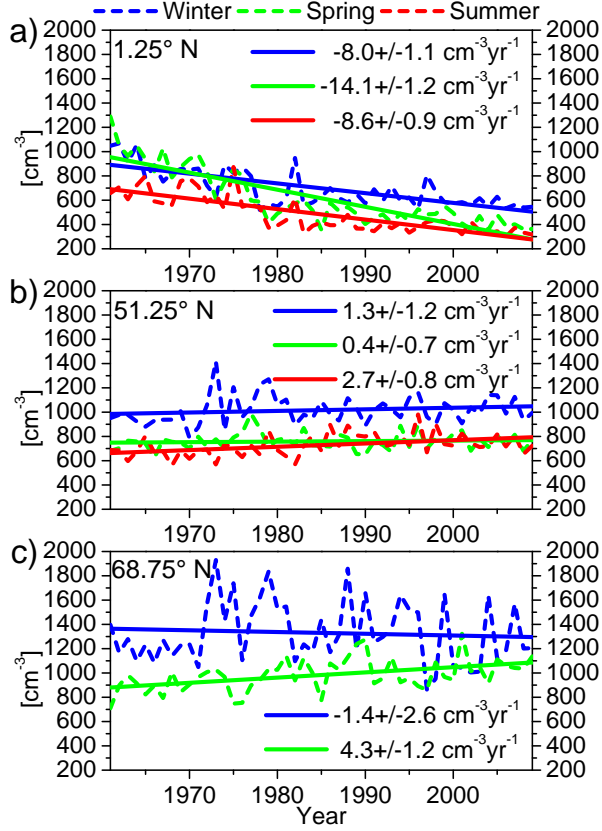

Figure 2. Long-term variations (dashed lines) and corresponding linear trends (solid lines) in the seasonally averaged nighttime mean concentration of the $\mathrm{OH}_{v=6}^{*}$ peak due to the variability in dynamics and temperature in low (a), middle (b), and high (c) northern latitudes for winter (blue lines), spring (green lines), and summer (red lines).

spring (1961/1962), and $344 \mathrm{~cm}^{-3}$ for summer (1968/1969). The number densities at low latitudes attain maxima of $1085.9 \mathrm{~cm}^{-3}$ in $1961 / 1962$ for winter, $1339.9 \mathrm{~cm}^{-3}$ in 1961 for spring, and $880.5 \mathrm{~cm}^{-3}$ in 1969 for summer. The $\mathrm{OH}^{*}$ layer at equatorial latitudes over the period 1961-2009 has higher number densities in winter and lower number densities in summer. It is important to note that the total changes in the $\mathrm{OH}^{*}$-peak number density over the entire period are comparable with the year-to-year variability, and they are larger than the standard deviations (SDs), which are 156.2, 239.2 , and $156.2 \mathrm{~cm}^{-3}$, for winter, spring, and summer, respectively. The strong decline in the $\mathrm{OH}^{*}$ concentration (especially in spring) to values of about $50 \%$ of the initial values is strikingly large. Unfortunately we do not have any direct experimental evidence to support such a decline. For solid confirmation the measurements would have to be non-interrupted at the same latitude during 49 years. Nevertheless, similar negative trends at equatorial latitudes were found by satellite measurements. Von Savigny (2015) presented trends of the vertically integrated emission rates of $\mathrm{OH}(3-1)$ band measured by SCIAMACHY at latitudes $10^{\circ} \mathrm{S}$ to $30^{\circ} \mathrm{N}$ between 2003 and 2011. Although the uncertainty appears substantial, a negative trend is discernible in Fig. 3 of von Savigny (2015) for each $10^{\circ}$ latitude band, which is not inconsistent with the results of the model.
At middle latitudes $\left(51.25^{\circ} \mathrm{N}\right.$, Fig. $\left.1 \mathrm{~b}\right)$ the trend is slightly positive for all seasons, with the largest value in summer $\left(2.2 \pm 1.0 \mathrm{~cm}^{-3} \mathrm{yr}^{-1}\right)$. The total changes over the entire period are $57.5 \pm 59.8,3.8 \pm 36.6$, and $109.0 \pm 46.7 \mathrm{~cm}^{-3}$ for winter, spring, and summer, respectively. The maximum of year-to-year variation amounts to 566.7, 200.3, and $309.0 \mathrm{~cm}^{-3}$, for winter (1973/1974), spring (1996/1997), and summer (1996/1997), respectively. The mean number densities for winter, spring, and summer seasons over 1961-2009 are $1040.0,800.2$, and $768.5 \mathrm{~cm}^{-3}$, respectively, with corresponding SDs of $120.6,73.1$, and $98.7 \mathrm{~cm}^{-3}$. Clearly, the number density at the peak of $\mathrm{OH}^{*}{ }_{v=6}$ in middle latitudes is largest in the winter season. The total change over the entire period is essentially smaller than the year-to-year variability and the SD. Despite the strong variability the trends of the number density (proportional to the airglow intensity) of $\mathrm{OH}^{*}$ should not be ignored for applications of airglow measurements in middle latitudes.

At high latitudes $\left(68.75^{\circ} \mathrm{N}\right)$ the trend is positive $(3.8 \pm 1.4$ $\left.\mathrm{cm}^{-3} \mathrm{yr}^{-1}\right)$ in spring but negative $\left(-1.5 \pm 2.6 \mathrm{~cm}^{-3} \mathrm{yr}^{-1}\right)$ in winter (Fig. 1c). It is not meaningful to show nighttime averages for high latitudes in summer. There is considerable extra-annual variability on the order of some years. The total changes in the number density in high latitudes over 1961-2009 amount to $-73.1 \pm 128.9 \mathrm{~cm}^{-3}$ in winter and $188.2 \pm 69.4 \mathrm{~cm}^{-3}$ in spring. The mean values for winter and spring seasons amount to $1347.0 \mathrm{~cm}^{-3}$ (SD of $258.6 \mathrm{~cm}^{-3}$ ) and $1032.6 \mathrm{~cm}^{-3}$ (SD of $149.3 \mathrm{~cm}^{-3}$ ), respectively. The maximum of year-to-year variability reaches $713.3 \mathrm{~cm}^{-3}$ in winter (1998-1999) and $373.3 \mathrm{~cm}^{-3}$ in spring (1990-1991). Thus, the total changes over the entire period amount to $\sim 10$ and $\sim 50 \%$ of the maximum of year-to-year variation for winter and spring, respectively. The values of total changes are comparable with SD (28 and $125 \%$ relative to SD in winter and spring, respectively). The winter season values are generally larger than those in spring.

The strongest trend can be seen at equatorial (low northern) latitudes, particularly for spring. The number density has approximately halved during these 49 years. However, the appearance of the trend is more that of a bi-stable behavior, the period after 1982 being in a low regime and before 1975 in a high regime, than a continuous decrease as the regression line seems to indicate. Due to scale and data overlap, this can hardly be seen in Fig. 1a, and only becomes clearly visible in Fig. 16b. At first glance, the strong decrease in low latitudes seems to be surprising as water vapor increased simultaneously due to anthropogenic growing methane oxidation, which is the source of hydrogen radicals. At low latitudes the behavior is rather nonuniform.

Figure 2 depicts long-term variations and corresponding linear trends of $\mathrm{OH}^{*}{ }_{v=6}$-peak number density due to the influence of the dynamics and temperature. The trend, corresponding to the variability in the dynamics and temperature, has the same sign for all seasons and latitudes as the total trend. It is valid for the number density of $\mathrm{OH}^{*}$ that the 


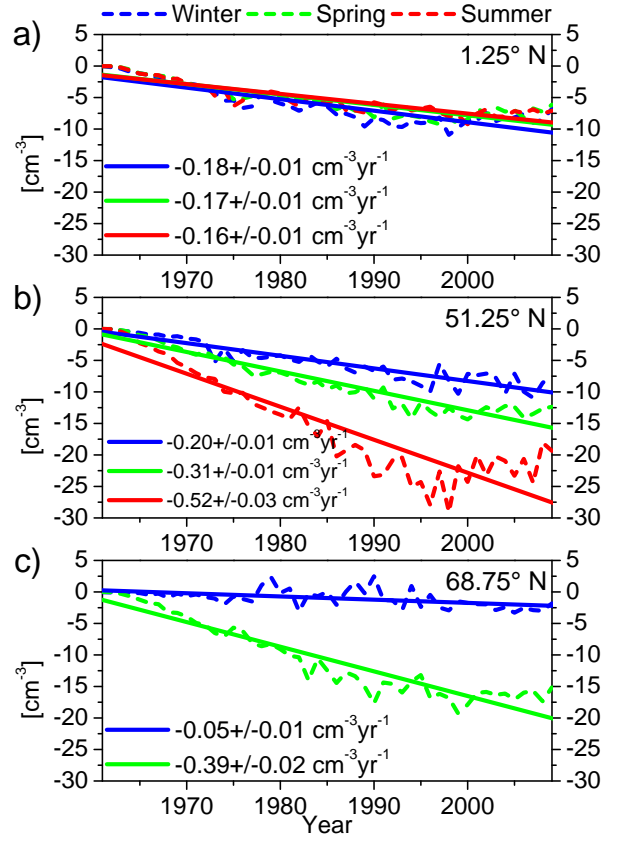

Figure 3. Long-term variations (dashed lines) and corresponding linear trends (solid lines) in the seasonally averaged nighttime mean concentration of the $\mathrm{OH}_{v=6}^{*}$ peak due to increase in GHGs in the CTM in low (a), middle (b), and high (c) northern latitudes for winter (blue lines), spring (green lines), and summer (red lines).

winter values are larger than those for spring and summer at all latitudes (with an exception at $1.25^{\circ} \mathrm{N}$ before about 1975 where the spring values are comparable with those of the winter). The strongest variability occurs at high latitudes in winter and the largest absolute values of the trend were found at equatorial latitudes. The relative deviations in trends due to dynamics and temperature from total trend $\left(\mathrm{RD}=100 \% \times\left(X_{\text {total }}-X_{\text {dyn }}\right) / X_{\text {total }}\right)$ amount to 3.5 to $4.4 \%$ at $1.25^{\circ} \mathrm{N},-8.3$ to $-23.6 \%$ at $51.25^{\circ} \mathrm{N}$ (excluding here the spring season, when the trend values are very small; consequently the relative deviations can become extremely large but the absolute deviations are not significant), and -12.9 to $-4.7 \%$ at $68.75^{\circ} \mathrm{N}$. The negative sign shows that the absolute values of trends due to dynamics and temperature are larger than those of the total trend. Thus, we can conclude that the total trends of the $\mathrm{OH}^{*}$ layer are mainly determined by changes in dynamics and temperature.

In Grygalashvyly et al. (2014) the following equation was derived for the $\mathrm{OH}^{*}$ density:

$\left[\mathrm{OH}^{*}\right] \approx B p[\mathrm{O}] / T^{3.4}$,

where $B$ is a constant and $p$ is the pressure. The number density at the peak of the $\mathrm{OH}^{*}$ layer is directly proportional to the atomic oxygen number density, which is ultimately determined by vertical fluxes, and inversely proportional to $T^{3.4}$. However, atomic oxygen also depends on temperature reducing the temperature sensitivity.

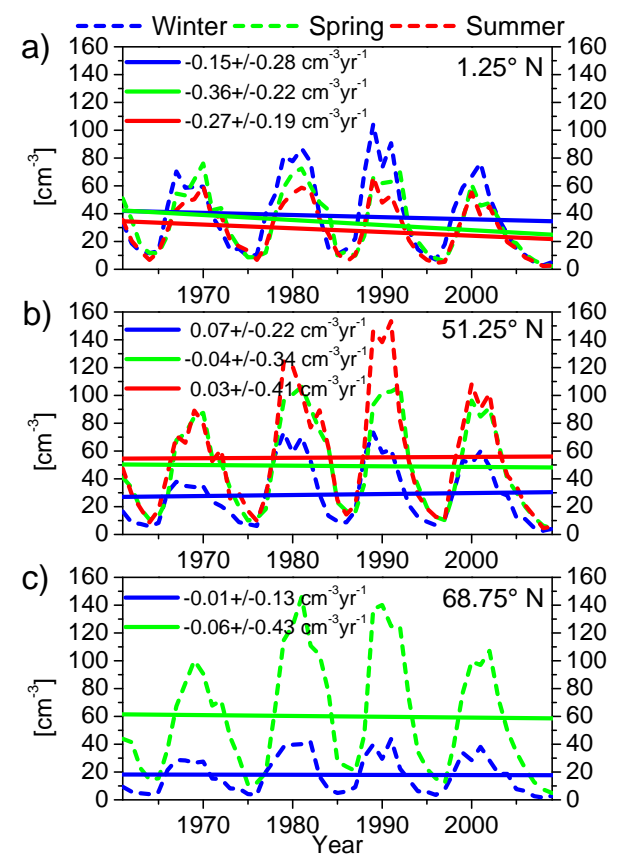

Figure 4. Long-term variations (dashed lines) and corresponding linear trends (solid lines) in the seasonally averaged nighttime mean concentration of the $\mathrm{OH}_{v=6}^{*}$ peak due to Lyman- $\alpha$ flux variability in low (a), middle (b), and high (c) northern latitudes for winter (blue lines), spring (green lines), and summer (red lines).

Figure 3 exhibits the separated impact of the increase in GHGs (run A minus run C) on the long-term variations (dashed lines) and linear trends (solid lines) of the $\mathrm{OH}^{*}{ }_{v=6}$ number density at low $\left(1.25^{\circ} \mathrm{N}\right.$, Fig. 3a), middle $\left(51.25^{\circ} \mathrm{N}\right.$, Fig. 3b), and high $\left(68.75^{\circ} \mathrm{N}\right.$, Fig. 3c) latitudes for winter (blue lines), spring (green lines), and summer (red lines). The direct chemical effect of GHG growth is negative at all latitudes and for all seasons. The total changes over the entire period are -25.5 to $-2.5 \mathrm{~cm}^{-3}$ depending on season and latitude. These values are negligible compared with the trend due to the dynamics and temperature. This finding is not surprising because, according to Eq. (4), the number density at the $\mathrm{OH}^{*}$ peak depends on only one chemical constituent, namely atomic oxygen $[\mathrm{O}]$, and additionally on the temperature, but the atomic oxygen long-term changes in the vicinity of the $\mathrm{OH}^{*}$ layer are mainly determined by the trend in vertical fluxes and temperature. The direct impact of the growth of GHGs on the $\mathrm{OH}^{*}$ layer is minor.

Figure 4 displays the long-term variations and the corresponding linear trends due to the direct photochemical effect of the Lyman- $\alpha$ variability (run A minus run B) at $1.25^{\circ} \mathrm{N}$ (Fig. 4a), $51.25^{\circ} \mathrm{N}$ (Fig. 4b), and $68.75^{\circ} \mathrm{N}$ (Fig. 1c) for winter (blue lines), spring (green lines), and summer (red lines). In the real atmosphere the 11-year solar cycle of the Lyman- $\alpha$ flux impacts the minor chemical constituents via photolysis, dynamics, and temperature. We discuss here the direct effect on the chemistry. The impact by the trend in the Lyman- $\alpha$ 


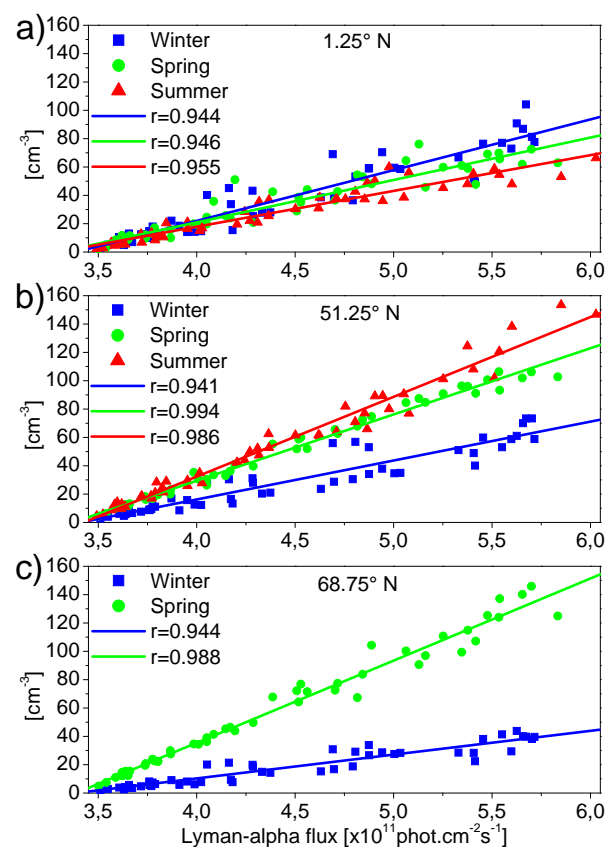

Figure 5. Dependence of the concentration of $\mathrm{OH}_{v=6}^{*}$ on the Lyman- $\alpha$ flux in low (a), middle (b), and high (c) northern latitudes for winter (blue lines), spring (green lines), and summer (red lines).

flux is essentially smaller than the total effect. The solar cycles are clearly mirrored in the data, but the absolute trend is completely negligible (the total changes over the entire period vary from -17.6 to $+3.4 \mathrm{~cm}^{-3}$ ) compared with the impact due to the dynamics and chemistry and also with regard to the variability within the 11-year solar cycle (the Lyman$\alpha$ flux varies by a factor of nearly 2 within a solar cycle, but the trend in Lyman- $\alpha$ amounts only to a few percent over the whole period of 49 years). Von Savigny (2015) reported that no 11-year solar cycle signatures are present in the $\mathrm{OH}$ emission altitude time series. Clearly, the dynamical influence overwhelms all other impacts.

The zero line in Fig. 4 corresponds to a Lyman- $\alpha$ radiation flux of $3.42 \times 10^{11}$ photons $\mathrm{cm}^{-2} \mathrm{~s}^{-1}$. The strongest variability in frame of the 11-year solar cycle period was found in mean latitudes in summer and amounts to about $150 \mathrm{~cm}^{-3}$ (Fig. 4b). In low latitudes (Fig. 4a) the largest minimummaximum range occurs in winter (up to about $100 \mathrm{~cm}^{-3}$ ). The weakest response of the $\mathrm{OH}^{*}$ layer on the 11-year solar cycle occurs in winter at high latitudes (Fig. 4c) and amounts to a maximum of $42 \mathrm{~cm}^{-3}$. In low latitudes (Fig. 4a) the amplitudes (the deviation from the mean) of the $\mathrm{OH}^{*}$ number density variation with the Lyman- $\alpha$ 11-year solar cycle are on average 38,34 , and $28 \mathrm{~cm}^{-3}$ for winter, spring, and summer, respectively. In middle latitudes (Fig. 4b) the amplitudes amount to $29 \mathrm{~cm}^{-3}$ in winter, $49 \mathrm{~cm}^{-3}$ in spring, and $55 \mathrm{~cm}^{-3}$ in summer. In high latitudes the winter and spring time amplitudes are 18 and $60 \mathrm{~cm}^{-3}$, respectively.
The response of the $\mathrm{OH}^{*}$ layer on the 11-year solar cycle is explained by photolysis of water vapor and molecular oxygen by Lyman- $\alpha$ radiation. In fact, in years of solar maxima, we have stronger dissociation of $\mathrm{O}_{2}$ by the Lyman- $\alpha$ radiation at $80-90 \mathrm{~km}$ and, consequently, more atomic oxygen and ozone. In years of solar maximum the dissociation of water vapor is stronger and the production of odd hydrogen and particularly of atomic hydrogen is consequently enhanced. Thus, the number density in the $\mathrm{OH}^{*}$ layer (and consequently the intensity of airglow) correlates with the Lyman- $\alpha$ flux.

Figure 5 illustrates these correlations of the peak number density of $\mathrm{OH}^{*}{ }_{v=6}$ for low (a), middle (b), and high (c) latitudes in winter (blue colors), spring (green colors), and summer (red colors). Like in the respective previous figures, the high summer latitude has been omitted. In low latitudes $\left(1.25^{\circ} \mathrm{N}\right.$, Fig. 5a) the rate of change $\Delta\left[\mathrm{OH}^{*}{ }_{v=6}\right] / \Delta \mathrm{Ly}-$ $\alpha\left[\mathrm{cm}^{-3} /\left(10^{11}\right.\right.$ photons $\left.\left.\mathrm{cm}^{-2} \mathrm{~s}^{-1}\right)\right]$ amounts to $35.8 \pm 1.8$ in winter (the correlation coefficient is $r=0.944$ ), 29.9 \pm 1.5 in spring $(r=0.946)$, and $25.3 \pm 1.1$ in summer $(r=0.955)$. At middle latitudes $\left(51.25^{\circ} \mathrm{N}\right.$, Fig. $\left.5 \mathrm{~b}\right)$ the rates are equal to $27.5 \pm 1.4(r=0.941)$ in winter, $46.7 \pm 0.8(r=0.994)$ in spring, and $56.3 \pm 1.4(r=0.986)$ in summer. The winter and spring rates of change (with corresponding correlation coefficient) in high latitude $\left(68.75^{\circ} \mathrm{N}\right.$, Fig. $\left.5 \mathrm{c}\right)$ amounts to $16.8 \pm 0.9(r=0.944)$ and $58 \pm 1.3(r=0.988)$, respectively. Therefore, the DPE on the number density in the $\mathrm{OH}^{*}$ layer does not play a great part in the long-term behavior and can be neglected, but it is essential for the 11-year variability.

In order to get an impression of the relative significance of trends due to the dynamics and temperature, the growth of GHGs, and the Lyman- $\alpha$ flux, in Fig. 6 we show the trends together with the total trend for different seasons and latitudes of the Northern Hemisphere. Figure $6 \mathrm{a}-\mathrm{d}$ illustrate the trends of the number density at the $\mathrm{OH}^{*}{ }_{v=6}$ peak in northern latitudes averaged over the night and season according to the total impact (a), dynamics and temperature (b), growth of GHGs in the CTM (c), and Lyman- $\alpha$ variability (d) for winter (blue line), spring (green line), and summer (red line). Note the different scales in Fig. 6a,b and c,d. The total trend (Fig. 6a) depends strongly on latitude. In low latitudes the trend is negative in all seasons, whereas a positive trend occurs particularly in midlatitudes. The calculation exhibits only a weak trend just at the Wuppertal latitude $\left(51.25^{\circ} \mathrm{N}\right)$. Figure $6 \mathrm{~b}$ shows the part of the total trends with respect to the trend in the dynamics. Figure $6 \mathrm{c}$ depicts the influence of the increasing GHGs and Fig. 6d that of the trend in the Lyman$\alpha$ flux. As one can recognize, the total trends are almost ultimately determined by the trend due of dynamics and temperature. The trends, due to the growth of GHGs and Lyman- $\alpha$ variability, are of minor importance and play nearly no role.

Figure 7 exhibits the difference between the peak heights of layers with vibrational numbers of 9 and $1, \Delta h_{9-1}=$ $h_{v=9}-h_{v=1}$, for the three latitudes and seasons under consideration. Only in low latitudes did $\Delta h_{9-1}$ increase considerably, where the total trends over the entire period reach 

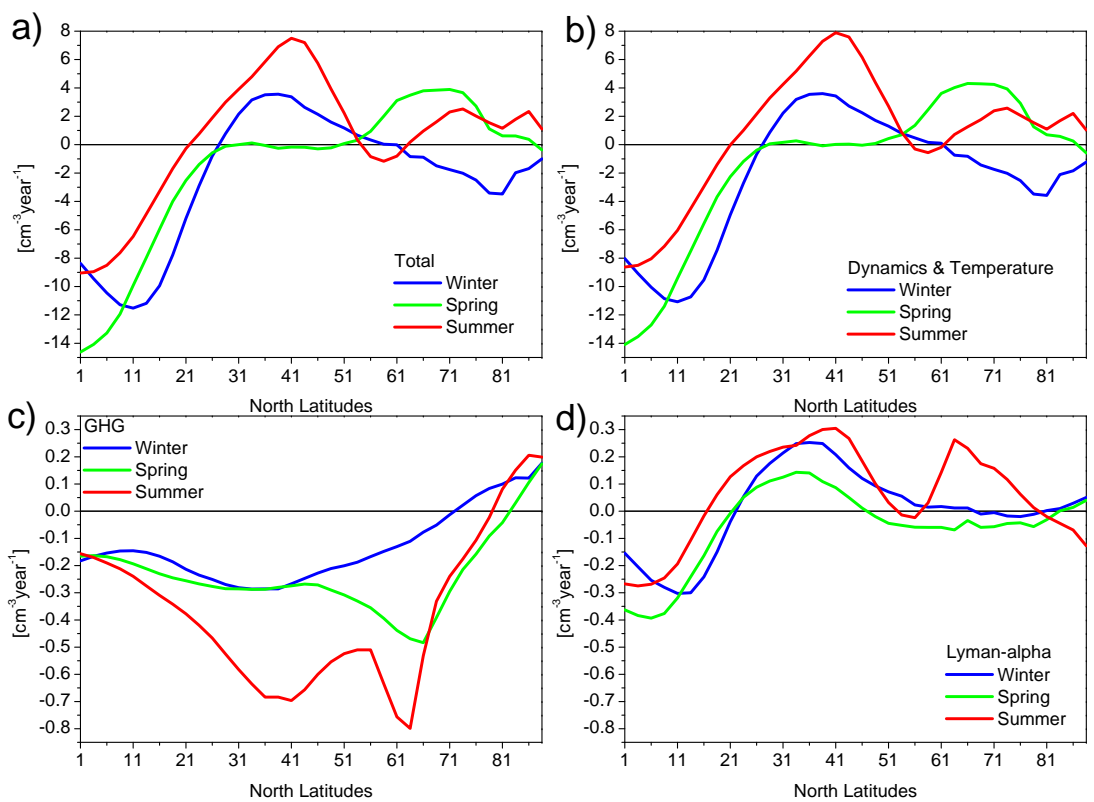

Figure 6. Trends of $\mathrm{OH}_{v=6}^{*}$-peak number density in the Northern Hemisphere averaged over the night and season due to the total impact (a), dynamics and temperature (b), growth of GHGs in the CTM (c), and Lyman- $\alpha$ variability (d) for winter (blue line), spring (green line), and summer (red line). Note that the scales are different in (a), (b) and (c), (d).

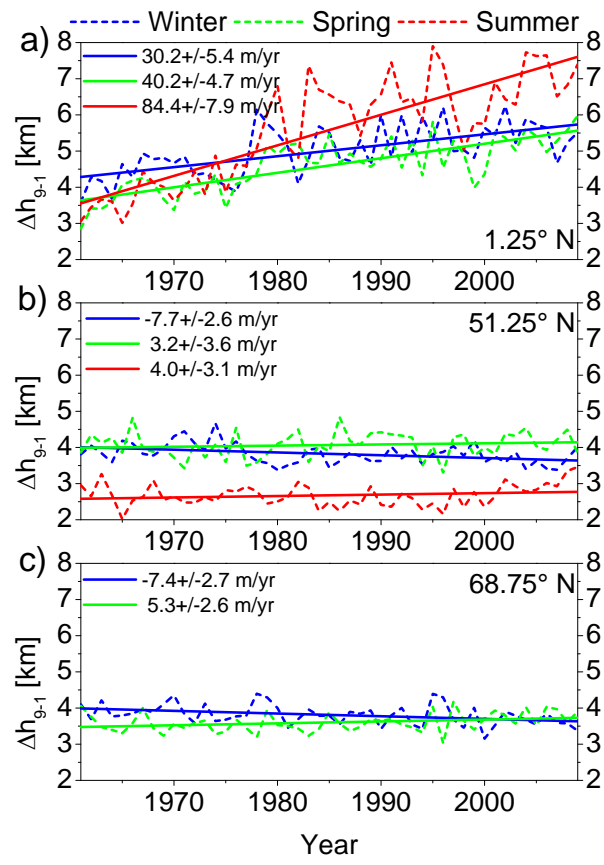

Figure 7. Trend of the distance of the $\mathrm{OH}^{*}$ layer for the three latitudes and seasons under investigation.

$4.14 \pm 0.38,1.97 \pm 0.23$, and $1.48 \pm 0.27 \mathrm{~km}$, in summer, spring, and winter, respectively. These values are comparable with the marked intra-annual variability at the considered latitudes. In high and middle latitudes the total trends of distance between the highest and lowest vibrational state do not exceed either the year-to-year variability (which amounts to about $1 \mathrm{~km}$ at these latitudes) or the intra-annual variability on the order of $2-3 \mathrm{~km}$ (Grygalashvyly et al., 2014). In low latitudes, $\Delta h_{9-1}$ seemingly jumps into a higher regime between 1975 and 1980.

\section{Correlations and intra-annual variability}

Important questions are those about the relations between the height of the $\mathrm{OH}^{*}$ peak, the $\mathrm{OH}^{*}$ number density and the corresponding temperatures. Figure 8 displays the pressure height of the $\mathrm{OH}^{*}$ peak over the $\mathrm{OH}^{*}{ }_{v=6}$ density for different seasons. We show correlations in so-called pressure heights (e.g., Lübken et al., 2013) because expression Eq. (4) shows dependence of concentration on pressure. In order to avoid confusion we point to the fact that the pressure heights differ from geometrical heights, and thus the peak of $\mathrm{OH}^{*}$ is placed higher than in geometrical coordinates. The color of the symbols and lines indicates the latitude. The correlation is very clear: the larger the density, the lower the peak lies. This is independent of season and latitude. The peak height decreases with increasing latitude. Qualitatively similar results were presented by Liu and Shepherd (2006) for data collected by WINDII on 29 August 1992, who showed an anticorrelation between the layer altitude and the integrated emission rates of the $\mathrm{OH}^{*}$ emission profiles for the latitudinal band between 32.5 and $37.5^{\circ} \mathrm{N}$. Also, Mulligan et al. (2009) found an inverse behavior between layer height and $\mathrm{OH}^{*}$ intensity in high latitude $\left(78^{\circ} \mathrm{N}\right)$ inferred from SABER measurements on the TIMED satellite. For an essentially larger time and latitudinal interval, von Savigny (2015) derived a 

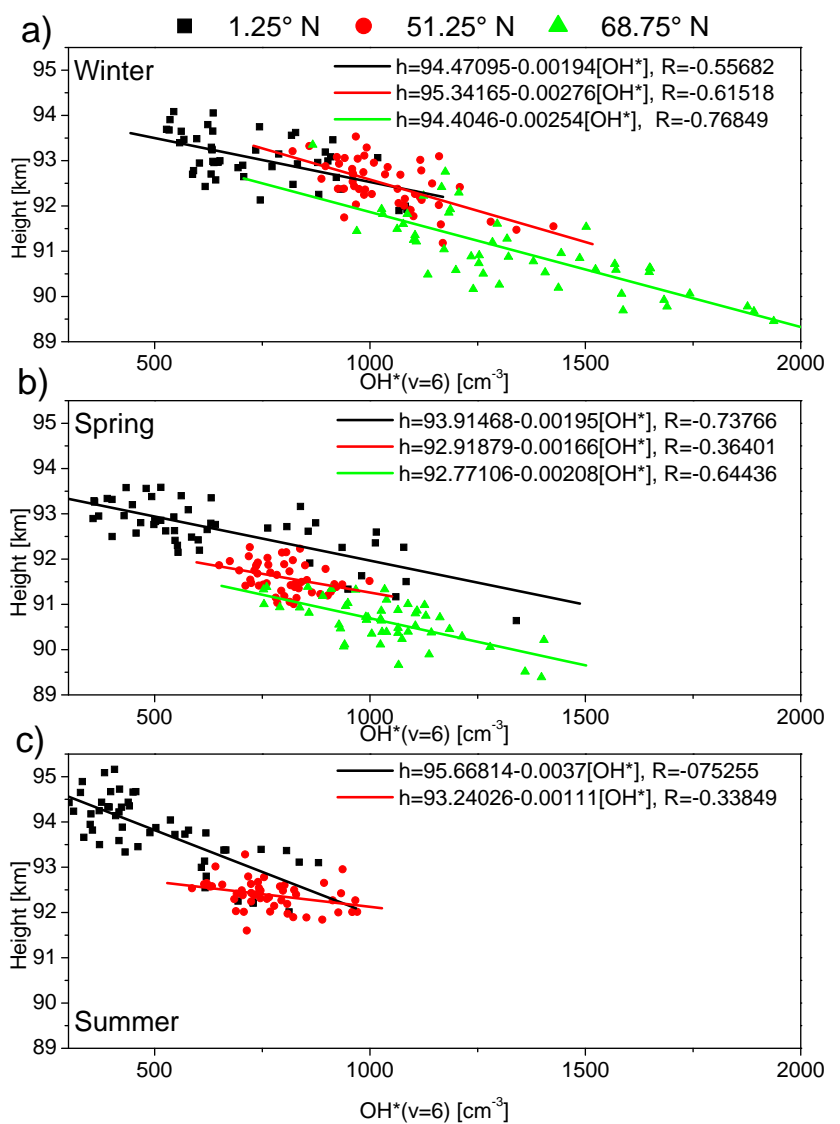

Figure 8. $\mathrm{OH}^{*}$ peak height in pressure coordinates versus the $\mathrm{OH}^{*}$ density for different seasons. The latitudes are indicated by color.

clear inverse relation between both parameters from SCIAMACHY measurements between $40^{\circ} \mathrm{S}$ and $70^{\circ} \mathrm{N}$ for the years 2004 to 2008. Such anticorrelation between height and number density is explained in Grygalashvyly et al. (2014): the concentration of $\mathrm{OH}^{*}$ is directly proportional to pressure and, consequently, inversely proportional to altitude.

The dominant intra-annual variation in the $\mathrm{OH}^{*}$ number density is the annual period. Its main driver is the annual cycle of solar insolation, where the strongest variation is in high latitudes. However, all other influences equally possess a distinct annual variation such as temperature, air density, water vapor, atomic hydrogen, atomic oxygen, and ozone density. The maxima occur at different dates in the year (e.g., ozone shows a clear semiannual variation). The same assertion is true for water vapor in low latitudes.

Figure 9 displays the results of a FFT (fast Fourier transform) analysis of the $\mathrm{OH}^{*}$ density in height of the peak at $1.25,51.25$, and $68.75^{\circ} \mathrm{N}$ latitude using data of the whole period of 49 years. Besides the pronounced annual period, which is clearest in high latitude (4 times larger amplitude than in middle or low latitudes), a distinct semiannual period occurs in all latitudes, although it is also more pronounced in high latitudes. The amplitudes rise with increasing latitudes
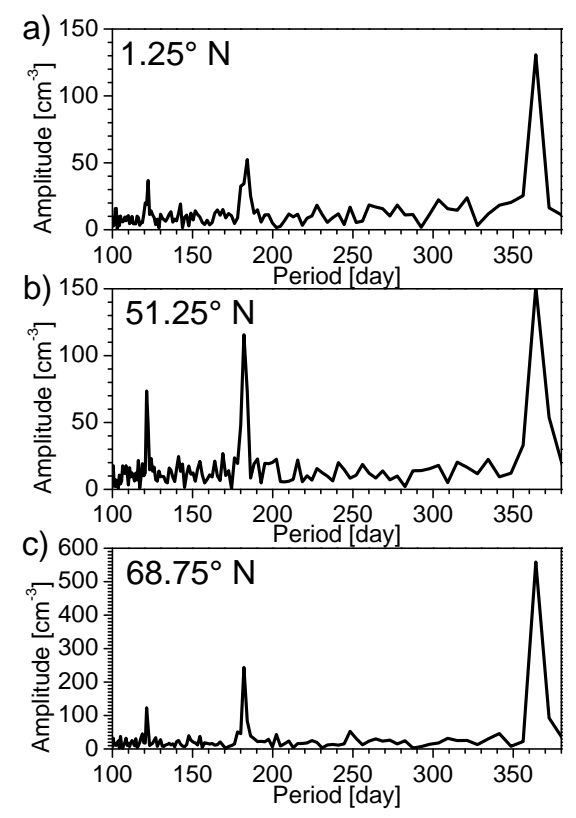

Figure 9. Results of an FFT (fast Fourier transform) analysis of the $\mathrm{OH}^{*}$ density in height of the peak at $1.25^{\circ} \mathrm{N}(\mathbf{a}), 51.25^{\circ} \mathrm{N}(\mathbf{b})$, and $68.75^{\circ} \mathrm{N}$ (c) latitude using the whole period of 49 years.

because the annual amplitude of the solar insolation also rises with increasing latitude because the annual amplitude of the solar insolation also rises with increasing latitude. The terannual variation in the $\mathrm{OH}^{*}$ density follows from the Fourier analysis. A period for a third year (4 months) occurs as a result of the superposition of different impacts on the $\mathrm{OH}^{*}$ density.

Additionally, we carried out a Fourier analysis for different latitudes from a mean year averaged over all 49 years. Figure 10 again presents the results for high, middle, and low latitudes. The amplitudes are on the same order as shown in Fig. 9, with the only exception being the semiannual period in low latitude. The amplitudes of the higher harmonics are also relatively small in low latitudes. In middle latitudes the semiannual amplitude is comparable with that of the annual period. The phase of the periods was calculated with the same Fourier analysis. Figure 10b, d, and f display the result as (negative) deviation from 1 January (a phase of 10 days, for example, means 22 December). Von Savigny and Lednyts'kyy (2013) and von Savigny (2015) reported a clear semiannual variation in the mean emission altitude at low latitudes with amplitude of $0.5-1 \mathrm{~km}$. A semiannual variation in the emission altitude is to be expected considering the annual height variations in the parameters that determine the $\mathrm{OH}^{*}$ chemistry.

The so-called two-day wave of different parameters in the mesopause region, such as the prevailing wind (e.g., Müller, 1972), temperature, ozone (Azeem et al., 2001), and other minor chemical constituents (e.g., Sonnemann and Grygalashvyly, 2005), was a subject of in- 

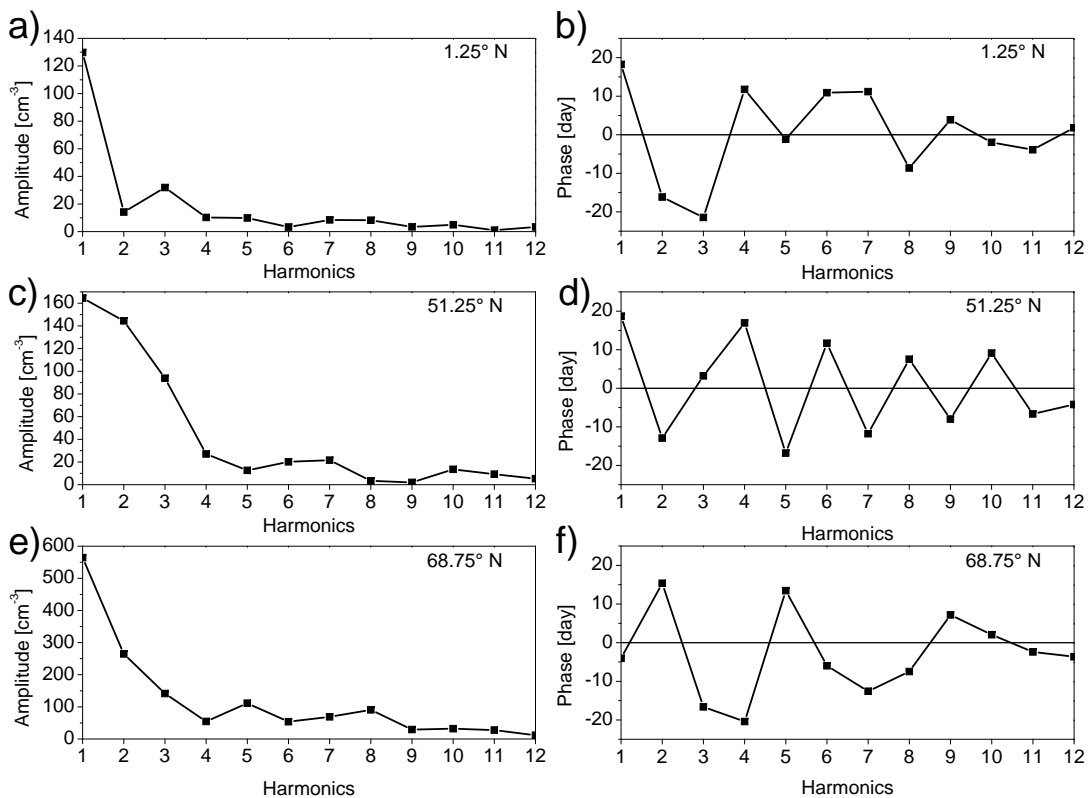

Figure 10. Fourier analysis from a mean year averaged over all 49 years for different latitudes showing the amplitude (left) and the phase (right).

tense investigation. Scheer and Reisin (2012) found a clear two-day periodicity in $\mathrm{OH}^{*}$ data (of vibrational number $v=6$ ) over Argentina. We calculated the relative mean value of the absolute next-amplitude difference of $\mathrm{OH}^{*}$ according to $d_{1}=2 /(N-1) \Sigma_{n=2, N}\left[\left(\mid \mathrm{OH}^{*}{ }_{n}\right.\right.$ $\left.\left.\mathrm{OH}^{*}{ }_{(n-1)} \mid\right) /\left(\mathrm{OH}_{n}^{*}+\mathrm{OH}^{*}{ }_{(n-1)}\right)\right]$. This formula stands for the day-to-day variability. For analysis, we choose periods of 1 month. A period-2 oscillation is marked by a sequence of values: e.g., high-low-high or low-high-low. In the case of a marked two-day variation over the whole period considered, $d_{1}$ is larger than it is in the case of quiet behavior; however, other possibly erratic variations are also marked by enhanced $d_{1}$ values. The chemical system responds often on a perturbation with a diluting period- 2 oscillation at the height of the $\mathrm{OH}^{*}$ maximum. A value of $d_{1}=0.5$ means that the average amplitude changes from day to day by $50 \%$ - a strong dayto-day variability.

We display 5-year sliding averages of the months January, April, July, and October, shown in Fig. 11a-d, respectively. We excluded two latitudinal grid points near the poles because these regions are possibly influenced by pole singularities; thus, the regions excluded are south of $83.75^{\circ} \mathrm{S}$ and north of $83.75^{\circ} \mathrm{N}$. The figures show some interesting features. Firstly, depending on month there are broad latitudinal belts of enhanced or reduced day-to-day variability. Also, depending on month, such belts occur, for example, around the equator or in high latitudes (enhanced) or in middle latitudes (diminished). Secondly, there is a hemispheric asymmetry, especially when comparing July with January. Thirdly, there seems to be a clear decreasing trend in the day-to-day vari- ability. Strong decreases occur in middle to high latitudes, particularly after equinoxes.

We calculate a latitudinal mean over all years. Figure 12a displays the result. We excluded again two grid points near the poles, but values at very high latitudes are influenced by polar day or polar night conditions. The picture is structurally symmetric with respect to corresponding seasons (April north compared with October south, and July north compared with January south) as mentioned in the preceding paragraph, but with hemispheric particularities. We calculated in the same way the latitudinal average of the nextbut-one amplitude difference, that is $\left|\mathrm{OH}^{*}{ }_{n+2}-\mathrm{OH}^{*}{ }_{n}\right|$. Figure $12 \mathrm{~b}$ shows the results. The curves exhibit structural similarities again, but with slightly stronger variations in the Southern Hemisphere. Large day-to-day variations are not a sufficient indication of period-2 oscillations but do not exclude them. The day-to-day variations seem to be triggered by the dynamics (by vertical wind and wave mixing transport conveying atomic oxygen and by temperature) and possible nonlinear effects in chemistry.

As mentioned, the main influences on the $\mathrm{OH}^{*}$ density are atomic oxygen and temperature. The main sink of atomic oxygen is the three-body reaction with molecular oxygen $\mathrm{O}_{2}$ and $M\left(\mathrm{~N}_{2} ; \mathrm{O}_{2}\right)$. Neglecting transports and other terms in the balance of atomic oxygen and that the characteristic time for $\mathrm{O}$ ranges on the order of 1 day at $87 \mathrm{~km}$ (meaning there is no equilibrium), atomic oxygen is very roughly $[\mathrm{O}] \approx F \times J_{\mathrm{O}_{2}} \times T^{2.3} /[M]\left([\mathrm{O}] \approx P_{\mathrm{O}} / L_{\mathrm{O}}\right.$; production term divided by the reduced loss term). $F$ is a factor containing different constants. $J_{\mathrm{O}_{2}}$, the dissociation rate of $\mathrm{O}_{2}$, represents a mean over the day. Hence, the temperature dependence of 

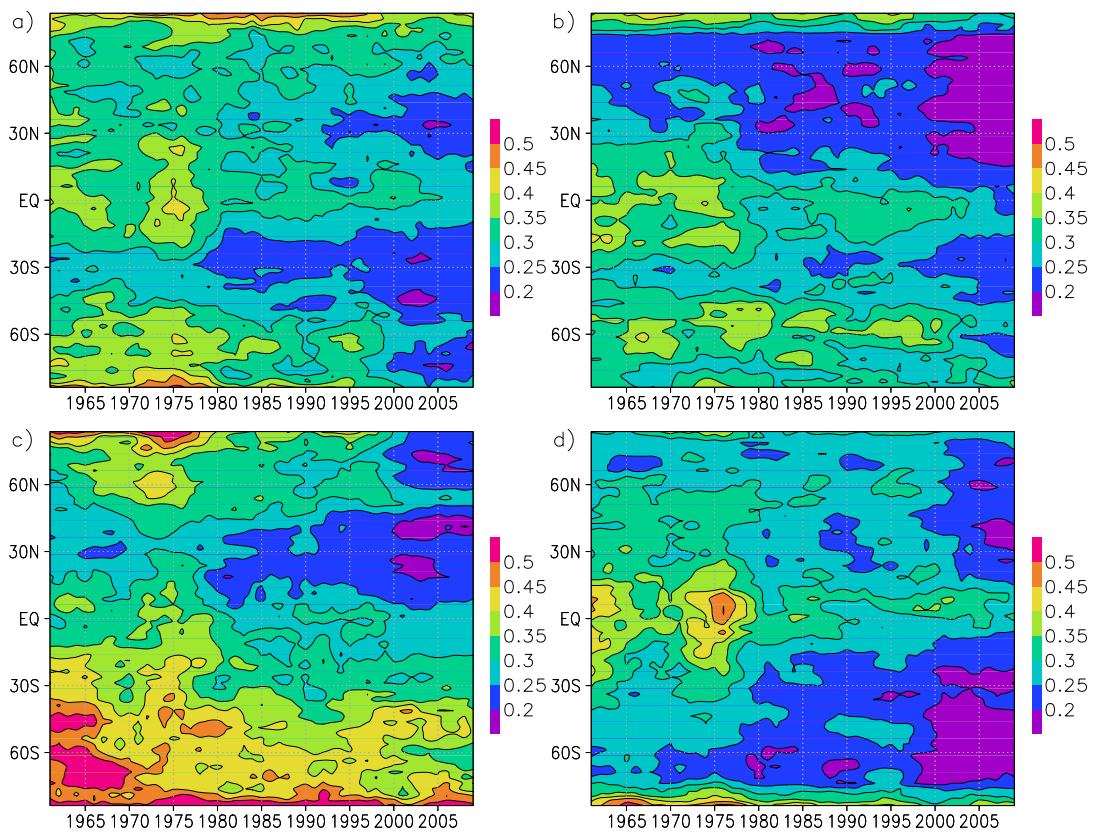

Figure 11. Five-year sliding average of the normalized mean of the absolute values of the next-amplitude difference for the months January (a), April (b), July (c), and October (d) (for explanation, see main text).
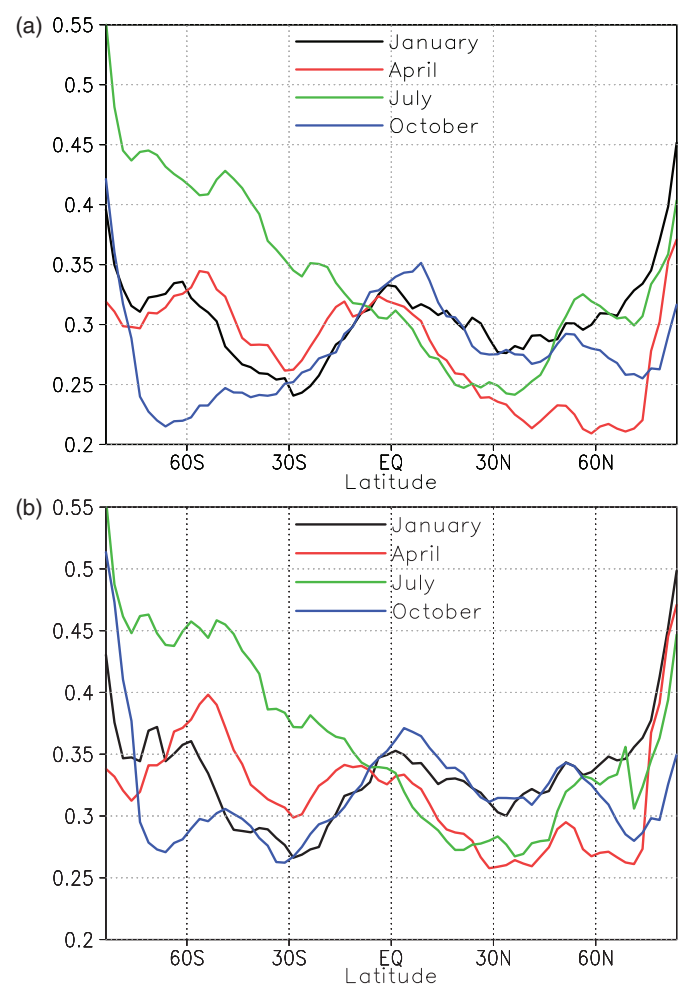

Figure 12. Latitudinal average over the entire period of the absolute value of the normalized difference of the mean next amplitude (a) and the next-but-one amplitude (b) for January, April, July, and October. atomic oxygen considerably reduces the temperature sensitivity of $\mathrm{OH}^{*}$ in Eq. (4). In other words, the higher the temperature, the smaller the loss term for $\mathrm{O}$.

Figure 13a-c show the annual variation in the temperature, $\mathrm{OH}^{*}$ density, and atomic oxygen density in 2009 (a year of small variability) at $1.25,51.25$, and $68.75^{\circ} \mathrm{N}$ at the height of the $\mathrm{OH}^{*}$ maximum (note the enlarged scale in Figure 13c). According to Eq. (4), atomic oxygen and temperature determine the $\mathrm{OH}^{*}$ density. The absolute and the relative annual, as well as day-to-day, variability for atomic oxygen and $\mathrm{OH}^{*}$ increases dramatically at high latitudes. The temperature has a strong annual variation at high latitudes but a less strong day-to-day variability which is larger at the equator. The variability in atomic oxygen triggered by vertical wind and gravity waves mixing transport has the strongest influence (Grygalashvyly et al., 2011, 2012). The temperature has a minimum in summer, whereas atomic oxygen possesses a broad maximum over winter between autumn and spring with a certain semiannual component. The figures illustrate the growing annual variation with increasing latitude.

Figure 14 displays the explicit factors of influence on the $\mathrm{OH}^{*}$ number density according to Eq. (2) at the height of the $\mathrm{OH}^{*}$ maximum at $51.25^{\circ} \mathrm{N}$ in 2009 again. According to this formula, ozone, atomic hydrogen, the number density, and the temperature determine the $\mathrm{OH}^{*}$ density. The figures also exhibit the day-to-day variability in the individual parameters. One can recognize the annual and, less clearly (e.g., in ozone with peaks near equinoxes, in atomic hydrogen with peaks in the end of spring and end of autumn), semiannual variation in the parameters. 


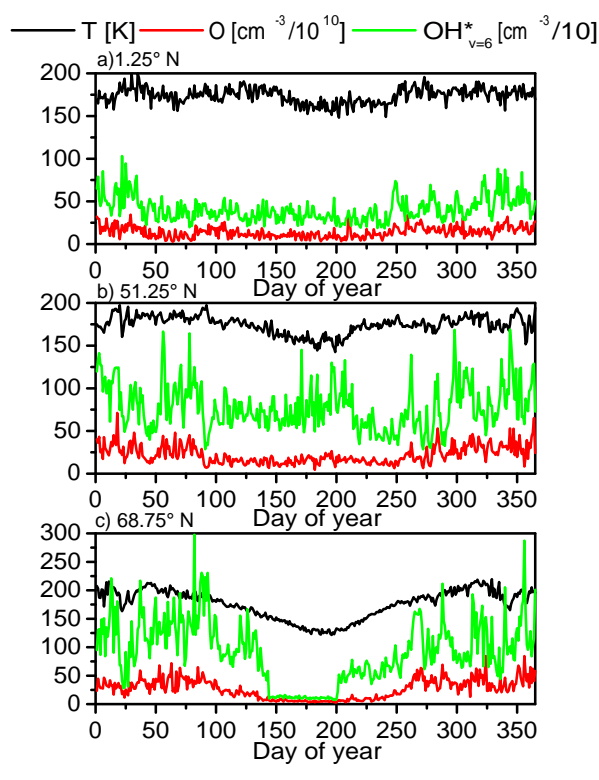

Figure 13. Annual variation in the temperature, $\mathrm{OH}^{*}$ density, and atomic oxygen density in 2009 at $1.25,51.25$, and $68.75^{\circ} \mathrm{N}$ at the height of the $\mathrm{OH}^{*}$ maximum. The gap in Fig. $13 \mathrm{c}$ in the $\mathrm{OH}^{*}$ density around summer solstice results from the polar day condition with permanent solar insolation at this latitude and strong reduction of the ozone density as one source gas of $\mathrm{OH}^{*}$.

\section{Discussion}

Different impacts influence the trend in number density of $\mathrm{OH}^{*}$. We know that the zonal wind due to the zonal wind effect on photochemistry (Sonnemann, 2001; Sonnemann and Grygalashvyly, 2003; Sonnemann et al., 2007; Grygalashvyly et al., 2008; Hartogh et al., 2011) has a considerable influence particularly on the nighttime ozone distribution. Changes in the (zonal) wind patterns result in changes in the $\mathrm{OH}^{*}$ distribution. Also, changes in gravity wave activity impact the distribution of chemical minor constituents by wave mixing transport only in the mesopause region (Grygalashvyly et al., 2011, 2012). The photochemical rate constants depend on temperature. The shrinking of the middle atmosphere due to cooling by $\mathrm{CO}_{2}$ and decreasing ozone shifts, in essence, only levels of constant mixing ratios downward, but the temperature also acts directly on the chemistry. Ozone increases if the temperature decreases (this fact also damps the anthropogenic ozone loss in the stratosphere). A cooling at the $\mathrm{OH}^{*}$ layer should entail a positive trend in the number density, but other reaction rates also depend on temperature, so that the net effect cannot be assessed by such simple considerations.

There is, of course, an occurrence of an 11-year signal, due to the variation in the Lyman- $\alpha$ radiation. However, when comparing the 11-year signal with the signal due to changing dynamics (Figs. 4 with 2), the latter is essentially stronger, as it overwhelms the Lyman- $\alpha$ signal, and thus the solar cycle is not clearly recognizable in the total trend. The Fourier analysis revealed an annual, a semiannual, and a terannual period in the data. The semiannual cycle of $\mathrm{OH}^{*}$ is essentially produced by the semiannual cycle of ozone. The relatively strong solar cycles 21 and 22 occur in the center of the whole period under consideration, and thus no marked Lyman- $\alpha$ trend exists. The trend in Lyman- $\alpha$ is small compared with the variation in the Lyman- $\alpha$ flux within a solar cycle. The Lyman- $\alpha$ signal is strongest during summer in middle to high latitudes. The increase in GHGs does not play a great part in the $\mathrm{OH}^{*}$ trend, although water vapor increased during that time due to rising methane concentration. The tendency in $\mathrm{OH}^{*}$ due to increasing GHGs is always slightly negative.

In high and middle latitudes the annual cycle dominates in some relevant trace gases such as water vapor or atomic oxygen. The reason for this is that the solar insolation possesses a strong annual cycle, also driving the large-scale circulation. In low and equatorial latitudes, the circulation tends towards a semiannual variation, mirrored in the distribution of the minor constituents. A weak semiannual variation in the water vapor distribution was first observed by Nedoluha et al. (1996) at Table Mountain, California, USA $\left(34.4^{\circ} \mathrm{N}\right)$. Körner and Sonnemann (2001) found, in global calculations, clear semiannual variation in mesospheric water vapor in low latitudes formed by vertical wind patterns. However, the response in the mesopause region differs from that in the mesosphere.

The semiannual variation in $\mathrm{OH}^{*}$, as derived from the Fourier analysis, mirrors in essence the semiannual variation in ozone, and this reflects the semiannual variation in atomic oxygen and the temperature. However, in this simple picture we have to take into consideration the semiannual variation in atomic hydrogen resulting from the variation in water vapor destroying ozone on the one hand and producing $\mathrm{OH}^{*}$ on the other hand. In a rather simplified picture is $\left[\mathrm{OH}^{*}\right] \sim\left[\mathrm{O}_{3}\right][\mathrm{H}]$ and with $\left[\mathrm{O}_{3}\right] \sim[\mathrm{O}] /[\mathrm{H}]$ during nighttime follows very roughly $\left[\mathrm{OH}^{*}\right] \sim[\mathrm{O}]$ as derived in Eq. (5). Atomic oxygen is very important for the formation of $\mathrm{OH}^{*}$. However, we have to consider that the nighttime chemical system is not in an equilibrium state but that all acting constituents are characterized by a considerable diurnal variation.

The photochemical system presents a driven nonlinear chemical oscillator (Sonnemann and Fichtelmann, 1987). This oscillator can create transient period-2 oscillations. Under the action of vertical flux of atomic hydrogen, it can also show a bi-stable behavior (Yang and Brasseur, 1994). Indications for a bi-stable behavior may be given by sudden strong steps in the $\mathrm{OH}^{*}$ density, as they sometimes occur in the calculated data. Winick et al. (2009) reported measurements of an $\mathrm{OH}$ layer derived from SABER data that was $5-8 \mathrm{~km}$ lower than normal but twice as bright in the unusual boreal winters of 2004 and 2006.

Figure 15 shows, in a latitude-time section, the annual sliding average over all years of the mean nighttime num- 

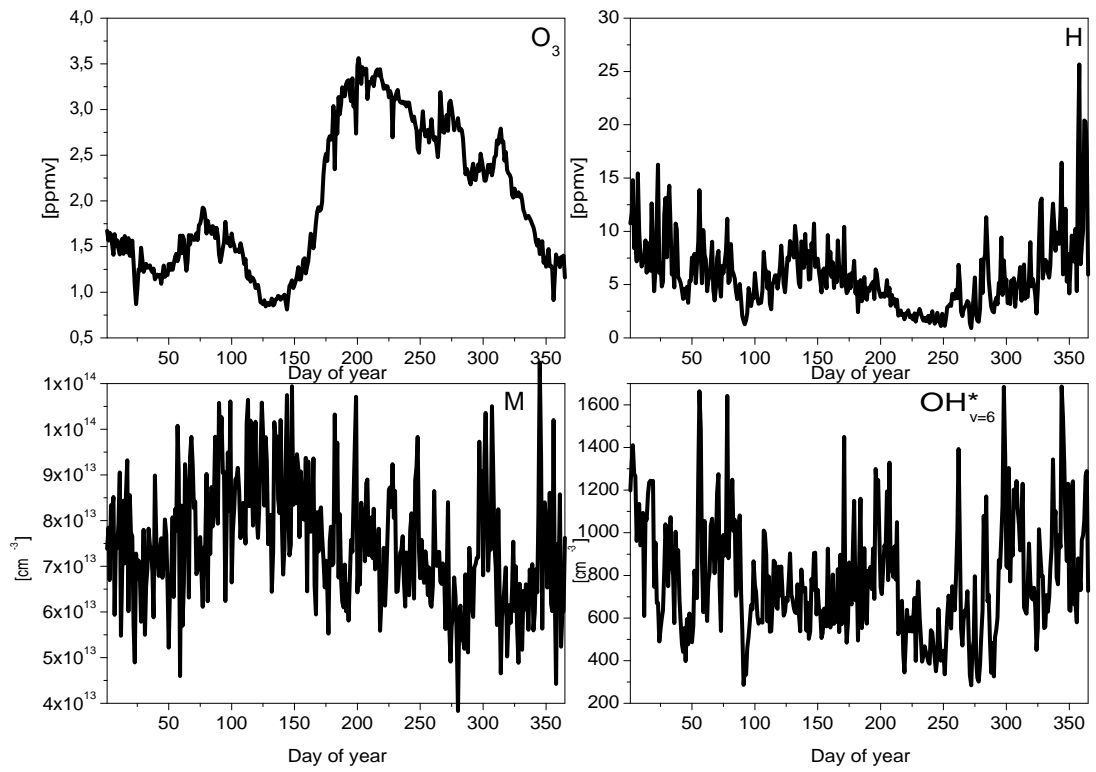

Figure 14. Explicit factors of influence on the $\mathrm{OH}^{*}$ number density according to Eq. (2) at height of $\mathrm{OH}^{*}$ maximum at $51.25^{\circ} \mathrm{N}$ in 2009 .

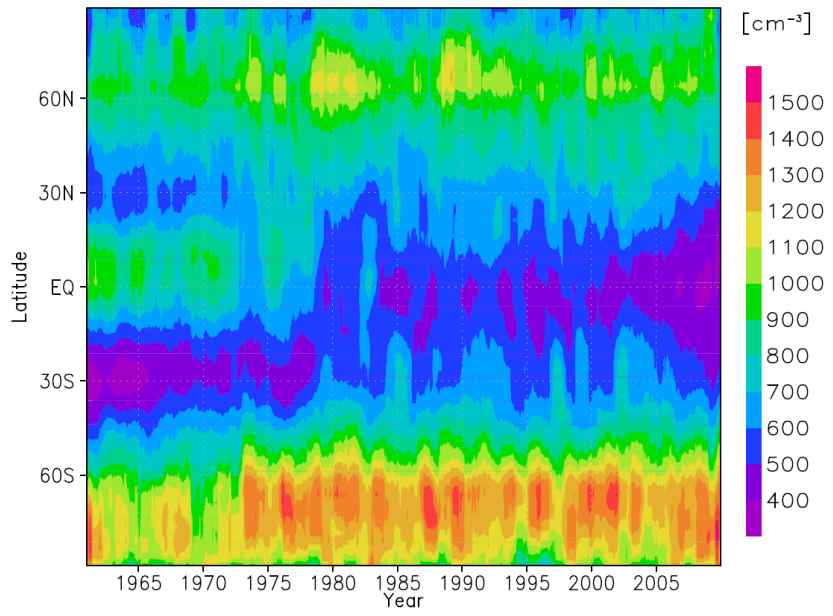

Figure 15. Annual sliding average of mean nighttime number density of $\mathrm{OH}_{v=6}^{*}$ at height of maximum.

ber density of $\mathrm{OH}^{*}{ }_{\nu=6}$ at its maximum height. The figure also exhibits a clear hemispheric asymmetry with highest values in high southern latitudes. The values vary with a period slightly longer than 2 years. There is a strong negative trend at equatorial latitudes before 1980, as already shown in Figs. 1 and 2. The appearance looks like a bi-stable regime jumping into a lower state. At other latitudinal belts, a step from low to high values occurs. The behavior is likely be triggered by the dynamics.
The time series sometimes exhibits a sudden change in trend. Often such changes are identified arbitrarily. In order to search for such step-like change in the behavior of the trend, we developed a program, termed SSTS (Search for Steps in Time Series; see Appendix A for code), based on a least-squares procedure and applied to the $\mathrm{OH}^{*}$ (or other) data. The weighted correlation coefficient $\left(r_{\text {weight }}\right)$ describes the method qualitatively. It is $r_{\text {weight }}=\left(n_{1} \times r_{1}+(n-\right.$ $\left.\left.n_{1}\right) \times r_{2}\right) / n>r$, with $n$ being number of years of the time series, $n_{1}$ being number of years before the change or step occurred, and $r_{i}$ being correlation coefficients ( $i=1$ or 2$)$ of both separate correlation coefficients. The quantity $r$ stands for the correlation coefficient of the trend that is not split into two separate trends. In the code, the sum of the least-squares values of each combination of $n_{1}$ with $\left(n-n_{1}\right)$ is calculated $\left(n_{1}\right.$ and $\left(n-n_{1}\right)>2$, respectively), and after that we determine the minimum of all least-squares values. For a clear step in the data series, the minimum is clear, too. Sometimes additional relative minima occur, indicating further changes in the time series. This procedure permits the finding of an obvious change in the trend on a mathematical basis.

Figure $16 \mathrm{a}-\mathrm{c}$ present three examples of sudden changes in the trend. The scale is different in each figure. Clearly, in some cases, the gradient of the regression lines changes considerably. A sudden break in the temperature trend at $87 \mathrm{~km}$ in 2001/2002 derived from $\mathrm{OH}^{*}$ measurements at Wuppertal $\left(51^{\circ} \mathrm{N}\right)$ between 1994 and 2004 (Offermann et al., 2006) demonstrates the relevance of such an analysis. An example of a sudden dramatic change in temperature trend in the mesopause is shown in Fig. 4 in the paper of Lübken et al. (2009). The trend lines drawn were identified visually. Beig (2011) also published a break in the temperature trend 


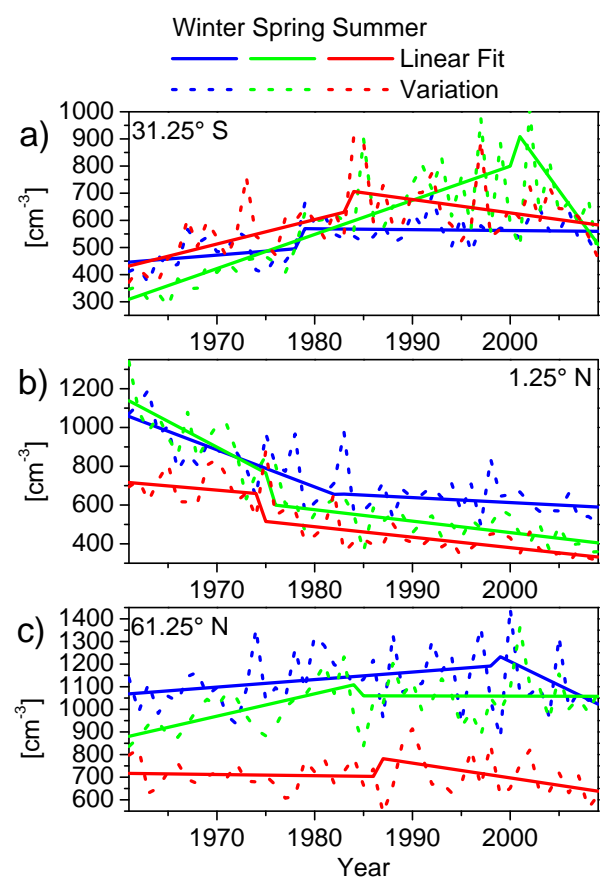

Figure 16. Three arbitrary examples of changing trend calculated by the program SSTS. Note different scales.

derived from $\mathrm{OH}$ airglow measurements. We will not attempt to find the reason for the changes in our results because the cause is often complex (changing dynamics, effects of nonlinear chemistry, nonuniform database used in the models, etc.).

The nonlinearity of the photochemistry amplifies the variability in the chemical minor constituents. On the one hand, belts of enhanced day-to-day variability point to nonlinear effects in the chemistry. On the other hand, as the dynamics have the strongest influence on the trend, varying vertical and zonal winds, or planetary waves and tidal wave activity, can produce a large day-to-day variability (von Savigny et al., 2015). However, this finding should be investigated more thoroughly.

\section{Summary and conclusions}

A large body of publications dealt with problems of excited hydroxyl. The long-term observations permit conclusions about temperature trends and changes in the composition of important minor constituents. However, in the observations a serious problem arises from the decrease in the height of the $\mathrm{OH}^{*}$ layer due to the cooling of the middle atmosphere by rising $\mathrm{CO}_{2}$ concentrations, and also from the decrease in ozone - particularly in the stratosphere (SMA effect). Thus, one has to take into account this decline when interpreting observed trends.

We calculated the separated impacts on the trend by changing solar radiation, the increase in GHGs, and the influence of the varying dynamics, which is also driven by increasing
GHGs and changing solar activity. In this context, "dynamics" refers to all parameters including temperature calculated by the dynamical model LIMA. The separated signal of the solar cycle variation is clear to see, but the long-term trend due to the trend in the Lyman- $\alpha$ flux is very small. The impact because of anthropogenic increase in GHGs, especially the increase in the methane concentration, is also small. The main reason for this consists in the fact that, if the mixing ratio of atomic hydrogen increases on account of rising humidity of the middle atmosphere, ozone decreases, compensating partly for the production of $\mathrm{OH}^{*}$ by the reaction of atomic hydrogen with ozone. This effect is, however, not so simple, because the chemical system represents a driven nonlinear chemical oscillator marked by a very intricate response, and the dynamics also control the distribution of the acting minor constituents. Hence, the reaction is highly variable depending on latitude, season, and different aeronomic conditions such as the particular composition of trace gases, the temperature, or the Lyman- $\alpha$ flux. Although the long-term trend of the $\mathrm{OH}^{*}$ number density, perhaps with the exception of low latitudes, is relatively small, the extra-annual variation is often high, demonstrating the sensitive response of the system on weak variations in the acting parameters. The behavior, depending on latitude, is not uniform and may point to a different dominating chemical regime, as is indicated by steps in the trend.

The strongest impact on the $\mathrm{OH}^{*}$ trend results from the dynamical output of the model. As no reference year with regard to the dynamics can be defined, the separated influence of the dynamics on the trend can be calculated to first order from the difference of the trend of the so-called real case minus the sum of the influence of the Lyman- $\alpha$ radiation plus the influence of the GHGs. The chief finding is that the main influence on the trend results from the changing dynamics. 


\section{Appendix A: Fortran code SSTS}

\section{PROGRAM SSTS}

$\mathrm{C}$

$\mathrm{C} n$ - stands for the number of years of the time series

$\mathrm{C}$ oh(i) $-\mathrm{OH}^{*}$ concentration in year $\mathrm{i}$

$C$ year(i) - year

$\mathrm{C}$ a1, b1, a2, b2 - parameters for the regression lines 1 and 2

$\mathrm{C} x(\mathrm{i})$ - value of the regression line in year $\mathrm{i}$.

$\mathrm{C} h 1$ - sum of the least-squares values

C From year jd to year $(j d+1)$ the step occurs in the trend

$\mathrm{C}-\mathrm{C}$

integer $\mathrm{i}, \mathrm{j}, \mathrm{i} 0, \mathrm{n}, \mathrm{n} 3, \mathrm{n} 4, \mathrm{~m}, \mathrm{~m} 1, \mathrm{lp}, \mathrm{l}$

integer jd, jd1, jd2

real*4 am, bm, c1, c2, c3, c4

real*4 oh(49), year(49), f1(49), g1(49)

real*4 a1(49), a2(49), x(49)

real*4 b1(49), b2(49), h1(49)

real $* 4$ as, bs, $g, f, d$

OPEN (11,FILE $=$ "TESTFILE.txt", form = "formatted")

$\operatorname{OPEN}(23, \mathrm{FILE}=$ "TREND.txt", form $=$ "formatted")

$\operatorname{OPEN}(25, \mathrm{FILE}=$ "PARAMETERS.txt",

form $=$ "formatted")

$\mathrm{n}=49$

$\mathrm{n} 3=\mathrm{n}-3$

$\mathrm{n} 4=\mathrm{n}-4$

do $\mathrm{i}=1, \mathrm{n}$

$\operatorname{read}(11,12)$ oh(i)

year(i) $=$ dble(i)

enddo

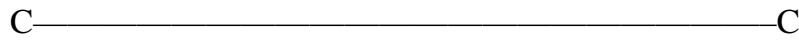

$\mathrm{am}=2$

$\mathrm{bm}=\operatorname{dble}(\mathrm{n})-2$

do $\mathrm{i}=3, \mathrm{n} 3$

$\mathrm{am}=\mathrm{am}+1$

$\mathrm{bm}=\mathrm{bm}-1$

$\mathrm{c} 1=0 . \mathrm{d} 0$

$\mathrm{c} 2=0 . \mathrm{d} 0$

$\mathrm{c} 3=0 . \mathrm{d} 0$

$\mathrm{c} 4=0 . \mathrm{d} 0$

$\mathrm{m}=\mathrm{i}$

do $\mathrm{j}=1, \mathrm{~m}$

$\mathrm{c} 1=\mathrm{c} 1+\mathrm{oh}(\mathrm{j}) *$ year $(\mathrm{j})$

$\mathrm{c} 2=\mathrm{c} 2+\mathrm{oh}(\mathrm{j})$

$\mathrm{c} 3=\mathrm{c} 3+$ year $(\mathrm{j})$

$\mathrm{c} 4=\mathrm{c} 4+$ year $(\mathrm{j}) *$ year(j)

enddo

$\mathrm{a} 1(\mathrm{~m})=(\mathrm{c} 2 * \mathrm{c} 4-\mathrm{c} 1 * \mathrm{c} 3) /(\mathrm{am} * \mathrm{c} 4-\mathrm{c} 3 * \mathrm{c} 3)$

$\mathrm{b} 1(\mathrm{~m})=(\mathrm{c} 1-\mathrm{c} 2 * \mathrm{c} 3 / \mathrm{am}) /(\mathrm{c} 4-\mathrm{c} 3 * \mathrm{c} 3 / \mathrm{am})$

$\mathrm{C}-\mathrm{C}$

$\mathrm{f}=0 . \mathrm{d} 0$

do $\mathrm{j}=1, \mathrm{~m}$

$\mathrm{f}=\mathrm{f}+(\mathrm{oh}(\mathrm{j})-\mathrm{a} 1(\mathrm{~m})-\mathrm{b} 1(\mathrm{~m}) *$ year(j))**2

enddo

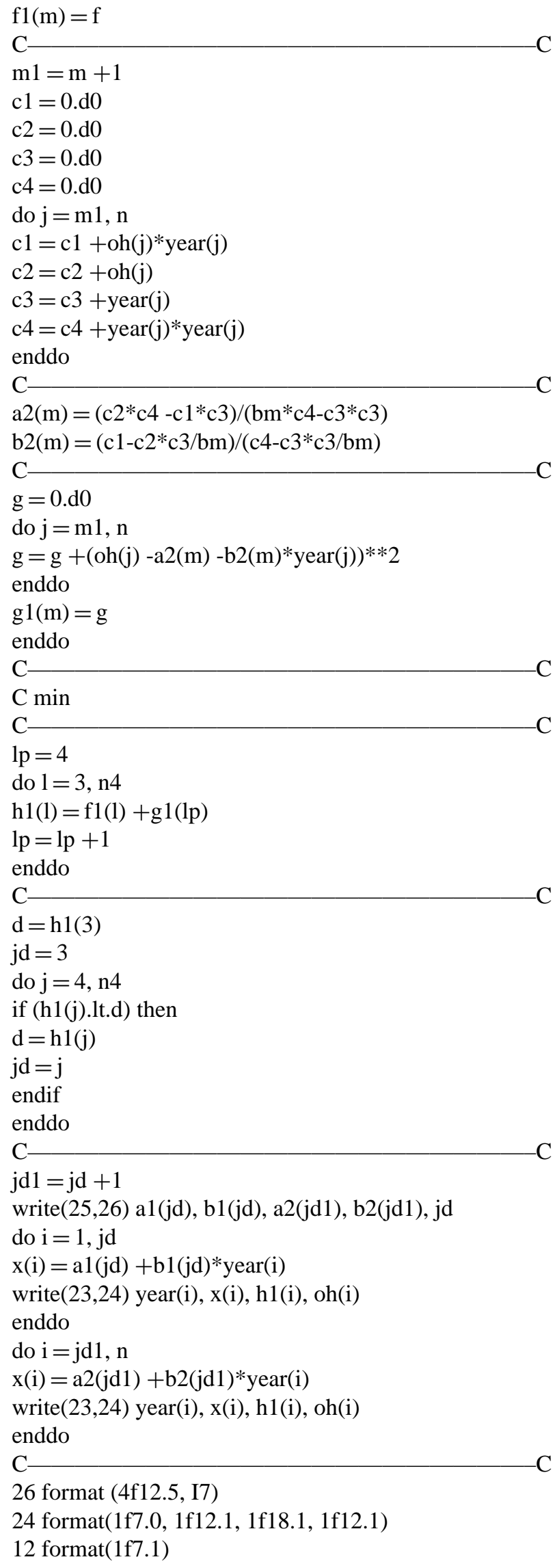


close(11)

close (23)

close (25)

$\mathrm{C}-$

stop

end 
Acknowledgements. The work was supported by DFG (Deutsche Forschungsgemeinschaft) project HA3261/7-1.

The article processing charges for this open-access publication were covered by the Max Planck Society.

The topical editor C. Jacobi thanks F. J. Mulligan and one anonymous referee for help in evaluating this paper.

\section{References}

Azeem, S. M. I., Palo, S. E., Wu, D. L., and Fridevaux, L.: Observations of the 2-day wave in UARS MLS temperature and ozone measurements, Geophys. Res. Lett., 28, 3147-3150, 2001.

Beig, G.: Long-term trends in the temperature of the mesosphere/lower thermosphere region: 1. Anthropogenic influences, J. Geophys. Res.-Space, 116, A00H11, doi:10.1029/2011JA016646, 2011.

Beig, G., Keckhut, P., Lowe, R. P., Roble, R. G., Mlynczak, M. G., Scheer, J., Fomichev, V. I., Offermann, D., French, W. J. R., Shepherd, M. G., Semenov, A. I., Remsberg, E. E., She, C. Y., Lübken, F. J., Bremer, J., Clemesha, B. R., Stegman, J., Sigernes, F., and Fadnavis, S.: Review of mesospheric temperature trends, Rev. Geophys., 41, 1015, doi:10.1029/2002RG000121, 2003.

Berger, U.: Modeling of the middle atmosphere dynamics with LIMA, J. Atmos. Terr. Phys., 70, 1170-1200, 2008.

Bittner, M., Offermann, D., and Graef, H. H.: Mesopause temperature variability above a midlatitude station in Europe, J. Geophys. Res., 105, 2045-2058, doi:10.1029/1999JD900307, 2000.

Bittner, M., Offermann, D., Graef, H. H., Donner, M., and Hamilton, K.: An 18-year time series of $\mathrm{OH}$ rotational temperatures and middle atmosphere decadal variations, J. Atmos. Sol. Terr. Phys.,64, 1147-1166, 2002.

Espy, P. J. and Stegman, J.: Trends and variability of mesospheric temperature at high-latitudes, Phys. Chem. Earth, 27, 543-553, 2002.

Espy, P. J., Stegman, J., Forkman, P., and Murtagh, D.: Seasonal variation in the correlation of airglow temperature and emission rate, Geophys. Res. Lett., 34, L17802, doi:10.1029/2007GL031034, 2007.

Feigin, A. M., Konovalov, I. B., and Molkov, Y. I.: Toward an understanding of the nonlinear nature of the atmospheric photochemistry: Essential dynamic model of the mesospheric phototochemical system, J. Geophys. Res., 103, 25447-25460, 1998.

Grygalashvyly, M. and Sonnemann, G. R.: Trends of mesospheric water vapor due to the increase of methane - A model study particularly considering high latitudes, Adv. Space Res., 38, 2394 2401, 2006.

Grygalashvyly, M., Hartogh, P., Medvedev, A., and Sonnemann, G. R.: The Doppler-Sonnemann Effect (DSE) on the Photochemistry on Mars, Adv. Geosciences, 19, 163-175, 2008.

Grygalashvyly, M., Becker, E., and Sonnemann, G. R.: Wave mixing effects on minor chemical constituents in the MLT-region: Results from a global CTM driven by high-resolution dynamics, J. Geophys. Res., 116, D18302, doi:10.1029/2010JD015518, 2011.

Grygalashvyly, M., Becker, E., and Sonnemann, G. R.: Wave mixing and effective diffusivity for minor chemical constituents in the mesosphere/lower thermosphere, Space Sci. Rev., 168, 333362, doi:10.1007/s11214-011-9857-x, 2012.

Grygalashvyly, M., Sonnemann, G. R., Lübken, F.-J., Hartogh, P., and Berger, U.: Hydroxyl layer: Mean state and trends at midlatitudes, J. Geophys. Res. Atmos., 119, 12391-12419, doi:10.1002/2014JD022094, 2014.

Hartogh, P., Jarchow, C., Sonnemann, G. R., and Grygalashvyly, M.: Ozone distribution in the middle latitude mesosphere as derived from microwave measurements at Lindau $\left(51.66^{\circ} \mathrm{N}, 10.13^{\circ} \mathrm{E}\right)$, J. Geophys. Res., 116, D04305, doi:10.1029/2010JD014393, 2011.

Körner, U. and Sonnemann, G. R.: Global three-dimensional modeling of water vapor concentration of the mesosphere-mesopause region and implications with respect to the noctilucent cloud region, J. Geophys. Res., 106, 9639-9651, 2001.

Liu, G. and Shepherd, G. G.: An empirical model for the altitude of the $\mathrm{OH}$ nightglow emission, Geophys. Res. Lett., 33, L09805, doi:10.1029/2005GL025297, 2006.

Lowe, R.: Long-term trends in temperature of the mesopause region at mid-latitude as measured by the hydroxyl airglow, paper presented at the 276 WE-Heraus-Seminar on Trends in the Upper Atmosphere, Wilhelm and Else Hareus-Stift., Kühlungsborn, Germany, 2002.

Lübken, F.-J., Berger, U., and Baumgarten, G.: Stratospheric and solar cycle effects on long-term variability of mesospheric ice clouds, J. Geophys. Res., 114, D00106, doi:10.1029/2009JD012377, 2009.

Lübken, F.-J., Berger, U., and Baumgarten, G.: Temperature trends in the midlatitude summer mesosphere, J. Geophys. Res., 118, doi:10.1002/2013JD020576, 2013.

Müller, H. G.: Long-period meteor wind oscillations, Philos. T. R. Soc. A, A271, 585-598, 1972.

Mulligan, F. J., Dyrland, M. E., Sigernes, F., and Deehr, C. S.: Inferring hydroxyl layer peak heights from ground-based measurements of $\mathrm{OH}(6-2)$ band integrated emission rate at Longyearbyen $\left(78^{\circ} \mathrm{N}, 16^{\circ} \mathrm{E}\right)$, Ann. Geophys., 27, 4197-4205, doi:10.5194/angeo-27-4197-2009, 2009.

Nedoluha, G. E., Bevilacqua, R. M., Gomez, R. M., Waltman, W. B., Hicks, B. C., Thacker, D. L., and Matthews, W. A.: Measurements of water vapor in the middle atmosphere and implications for mesospheric transport, J. Geophys. Res., 101, 21183-21193, 1996.

Offermann, D. and Gerndt, R.: Upper mesospheric temperatures from $\mathrm{OH}^{*}$-emissions, in: CIRA 1986, Part II, edited by: Rees, D., Barnett, J. J., and Labitzke, K., Adv. Space Res., 10, 217 221, 1990.

Offermann, D., Donner, M., Knieling, P., Hamilton, K., Menzel, A., Naujokat, B., and Winkler, P.: Indications of long-term changes in middle atmosphere transports, Adv. Space Res., 32, 16751684, 2003.

Offermann, D., Jarisch, M., Donner, M., Steinbrecht, W., and Semenov, A. I.: OH temperature re-analysis forced by recent variance increases, J. Atmos. Sol. Terr. Phys., 68, 1924-1933, doi:10.1016/j.jastp.2006.03.007, 2006.

Offermann, D., Hoffmann, P., Knieling, P., Koppmann, R., Oberheide, J., Riggin, D. M., Tunbridge, V. M., and Steinbrecht, W.: Quasi 2 day waves in the summer mesosphere: Triple structures of amplitudes and long-term development, J. Geophys. Res., 116, D00P02, doi:10.1029/2010JD015051, 2010. 
Reisin, E. R. and Scheer, J.: Searching for trends in mesopause region airglow intensities and temperatures at El Leoncito, Phys. Chem. Earth, 27, 563-569, 2002.

Reisin, E. R. and Scheer, J.: Gravity wave activity in the mesopause region from airglow measurements at El Leoncito, J. Atmos. Sol. Terr. Phys., 66, 655-666, 2004.

Reisin, E.R. and Scheer, J.: Evidence of change after 2001 in the seasonal behaviour of the mesopause region from airglow data at El Leoncito, Adv. Space Res., 44, 401-412, 2009.

Sander, S. P., Finlayson-Pitts, B. J., Friedl, R. R., Golden, D. M., Huie, R. E., Keller-Rudek, H., Kolb, C. E., Kurylo, M. J., Molina, M. J., Moortgat, G. K., Orkin, V. L., Ravishankara, A. R., and Wine, P. H.: Chemical Kinetics and Photochemical Data for Use in Atmospheric Studies, Evaluation Number 15, JPL Publication 06-2, Jet Propulsion Laboratory, Pasadena, California, USA, 2006.

Scheer, J. and Reisin, E. R.: Unusually low airglow intensities in the Southern Hemisphere midlatitude mesopause region, Earth Planets Space, 52, 261-266, 2000.

Scheer, J. and Reisin, E. R.: Statistical properties of nonlinear wave signatures in $\mathrm{OH}$ and $\mathrm{O}_{2}$ airglow brightness data observed at lower midlatitudes, J. Atmos. Sol. Terr. Phys., 72, 588-594, 2010.

Scheer, J. and Reisin, E. R.: An unusual airglow year at El Leoncito - evidence of chemical change?, 39th COSPAR Scientific Assembly 2012, Mysore, India, C2.2-0037-12, 2012.

Scheer, J., Reisin, E. R., and Mandrini, C. H.: Solar activity signatures in mesopause region temperatures and atomic oxygen related airglow brightness at El Leoncito, Argentina, J. Atmos. Sol.-Terr. Phys. 67, 145-154, 2005.

She, C.-Y. and Lowe, R. P.: Seasonal temperature variations in the mesopause region at mid-latitude: Comparison of lidar and hydroxyl rotational temperatures using WINDII/UARS height profiles, J. Atmos. Sol. Terr. Phys., 60, 1573-1583, 1998.

Sonnemann, G. R.: The photochemical effects of dynamically induced variations in solar insolation, J. Atmos. Sol. Terr. Phys., 63, 781-797, 2001.

Sonnemann, G. and Fichtelmann., B.: Enforced oscillations and resonances due to internal non-linear processes of photochemical system in the atmosphere, Acta Geod. Geophys. Hu., 22, 301311, 1987.

Sonnemann, G. and Fichtelmann, B.: Subharmonics, cascades of period doubling, and chaotic behavior of photochemistry of the mesopause region, J. Geophys. Res., 102, 1193-1203, 1997.

Sonnemann, G. R. and Grygalashvyly, M.: The zonal wind effect on the photochemistry within the mesosphere/mesopause region, Adv. Space Res., 32, 719-724, 2003.

Sonnemann, G. R. and Grygalashvyly, M.: On the two-day oscillations and the day-to-day variability in global 3-D-modeling of the chemical system of the upper mesosphere/mesopause region, Nonlin. Processes Geophys., 12, 691-705, doi:10.5194/npg-12691-2005, 2005.

Sonnemann, G., Ebel, A., Kremp, Ch., and Berger, U.: A threedimensional dynamic model of the photochemistry of the mesosphere, Proceedings International Scientific Colloquium on Impact of Emissions from Aircraft and Spacecraft Upon the Atmosphere, edited by.: Schumann, U. and Wurzel, D., 262-267, 1994.
Sonnemann, G., Kremp, Ch., Ebel, A., and Berger, U.: A threedimensional dynamic model of minor constituents of the mososphere, Atmos. Environm., 32, 3157-3172, 1998.

Sonnemann, G. R., Grygalashvyly, M., and Berger, U.: Autocatalytic water vapor production as a source of large mixing ratios within the middle to upper mesosphere, J. Geophys. Res., 110, D15303, doi:10.1029/2004JD005593, 2005.

Sonnemann, G. R., Grygalashvyly, M., Hartogh, P., and Jarchow, C.: Behavior of mesospheric ozone under nearly polar night conditions, Adv. Space Res., 38, 2402-2407, 2006 a.

Sonnemann, G. R., Grygalashvyly, M., and Berger, U.: Impact of a stratospheric warming event in January 2001 on the minor constituents in the MLT region calculated on the basis of a new 3D-model LIMA of the dynamics and chemistry of the middle atmosphere, J. Atmos. Sol. Terr. Phys., 68, 2012-2025, $2006 \mathrm{~b}$.

Sonnemann, G. R., Hartogh, P., Jarchow, C., Grygalashvyly, M., and Berger, U.: On the winter anomaly of the night-to-day ratio of ozone in the middle to upper mesosphere in middle to high latitudes, Adv. Space Res., 40, 846-854, 2007.

Sonnemann, G. R., Hartogh, P., Grygalashvyly, M., Li, S., and Berger, U.: The quasi 5-day signal in the mesospheric water vapor concentration at high latitudes in 2003 - a comparison between observations at ALOMAR and calculations, J. Geophys. Res., 113, D04101, doi:10.1029/2007JD008875, 2008.

Taylor, M. J., Espy, P. J., Baker, D. J., Sica, R. J., Neal, P. C., and Pendleton Jr., W. R.: Simultaneous intensity, temperature and imaging measurements of short period wave structure in the $\mathrm{OH}$ nightglow emission, Planet. Space Sci., 39, 1171-1188, 1991.

Taylor, M. J., Fritts, D. C., and Isler, J. R.: Determination of horizontal and vertical structure of an unusual pattern of short period gravity waves imaged during ALOHA-93, Geophys. Res. Lett., 22, 2837-2840, 1995a.

Taylor, M. J., Gu, Y. Y., Tao, X., Gardner, C. S., and Bishop, M. B.: An investigation of intrinsic gravity wave signatures using coordinated lidar and nightglow image measurements, Geophys. Res. Lett., 22, 2853-2856, 1995b.

Taylor, M. J., Pendleton Jr., W. R., Clark, S., Takahashi, H., Gobbi, D., and Goldberg, R. A.: Image measurements of short-period gravity waves at equatorial latitudes, J. Geophys. Res., 102, 26283-26299, 1997.

Uppala, S. M., Kallberg, P. W., Simmons, A. J.: The ERA-40 reanalysis, Q. J. Roy. Meteor. Soc., 131, 2961-3012, 2005.

von Savigny, C.: Variability of $\mathrm{OH}(3-1)$ emission altitude from 2003 to 2011: Long-term stability and universality of the emission rate-altitude relationship, J. Atmos. Sol--Terr. Phys., 127, 120 128, doi:10.1016/j.jastp.2015.02.001, 2015.

von Savigny, C. and Lednyts'kyy, O.: On the relationship between atomic oxygen and vertical shifts between $\mathrm{OH}$ Meinel bands originating from different vibrational levels, Geophys. Res. Lett., 40, 5821-5825, doi:10.1002/2013GL058017, 2013.

von Savigny, C., McDade, I. C., Eichmann, K.-U., and Burrows, J. P.: On the dependence of $\mathrm{OH}^{*}$ Meinel emission altitude on vibrational level: SCIAMACHY observations and model simulations, Atmos. Chem. Phys., 12, 8813-8828, doi:10.5194/acp-12-88132012, 2012.

von Savigny, C., Lednyts'kyy, O., Forbes, J. M., and Zhang, X.: Lunar semidiurnal tide in the terrestrial airglow, Geophys. Res. Lett., 42, 3553-3559, doi:10.1002/2015GL063567, 2015. 
von Zahn, U., Fricke, K. H., Gerndt, R., and Blix, T.: Mesospheric temperatures and the $\mathrm{OH}$ layer height as derived from groundbased lidar and $\mathrm{OH}^{*}$-spectrometry, J. Atmos. Terr. Phys., 49, 863-869, 1987.

Winick, J. R., Wintersteiner, P. P., Picard, R. H., Esplin, D., Mlynczak, M. G., Russel III, J. M., and Gordley, L. L.: OH layer characteristics during unusual boreal winters of 2004 and 2006, J. Geophys. Res., 114, A02303, doi:10.1029/2008JA013688, 2009.

Xu, J., Smith, A. K., Giang, G., Gao, H., Wei, Y., Mlynczak, M. G., and Russel III, J. M.: Strong longitudinal variations in the $\mathrm{OH}$ nightglow, Geophys. Res. Lett., L21801, doi:10.1029/2010GL043972, 2010.

Xu, J., Gao, H., Smith, A. K., and Zhu, Y.: Using TIMED/SABER nightglow observations to investigate hydroxyl emission mechanisms in the mesopause region, J. Geophys. Res., 117, D02301, doi:10.1029/2011JD016342, 2012.
Yamada, Y., Fukunishi, H., Nakamura, T., and Tsuda, T.: Breaking of small scale gravity wave and transition to turbulence observed in $\mathrm{OH}$ airglow, Geophys. Res. Lett., 28, 2153-2156, doi:10.1029/2000GL011945, 2001.

Yang, P. and Brasseur, G.: Dynamics of the oxygen-hydrogen system in the mesosphere, 1 . Photochemical equilibria and catastrophe, J. Geophys. Res., 99, 20955-20965, 1994.

Yee, J.-H., Crowley, G., Roble, R. G., Skinner, W. R., Burrage, M. D., and Hays, P. B.: Global simulations and observations of $\mathrm{O}(1 \mathrm{~S}), \mathrm{O}_{2}(1 \mathrm{~S})$ and $\mathrm{OH}$ mesospheric nightglow emissions, J. Geophys. Res., 102, 19949-19968, doi:10.1029/96JA01833, 1997. 